OPEN ACCESS

Edited by:

Christoph Fahlke,

Forschungszentrum Jülich, Germany

Reviewed by:

Adriano Martins,

Maimonides Medical Center.

United States

Aaron G. Roseberry,

Georgia State University,

United States

Richard Warth,

University of Regensburg, Germany

*Correspondence:

Richard Barrett-Jolley

RBJ@Liverpool.ac.uk;

RBJ@liv.ac.uk

Specialty section:

This article was submitted to

Membrane Physiology

and Membrane Biophysics,

a section of the journal

Frontiers in Physiology

Received: 18 March 2018

Accepted: 30 May 2018

Published: 06 July 2018

Citation:

Feetham $\mathrm{CH}$, O'Brien F and Barrett-Jolley R (2018) Ion Channels in the Paraventricular Hypothalamic Nucleus (PVN); Emerging Diversity

and Functional Roles.

Front. Physiol. 9:760

doi: 10.3389/fphys.2018.00760

\section{Ion Channels in the Paraventricular Hypothalamic Nucleus (PVN); Emerging Diversity and Functional Roles}

\author{
Claire H. Feetham ${ }^{1}$, Fiona O'Brien² and Richard Barrett-Jolley2* \\ ${ }^{1}$ Faculty of Biology, Medicine and Health, University of Manchester, Manchester, United Kingdom, ${ }^{2}$ Institute of Ageing and \\ Chronic Disease, University of Liverpool, Liverpool, United Kingdom
}

The paraventricular nucleus of the hypothalamus (PVN) is critical for the regulation of homeostatic function. Although also important for endocrine regulation, it has been referred to as the "autonomic master controller." The emerging consensus is that the PVN is a multifunctional nucleus, with autonomic roles including (but not limited to) coordination of cardiovascular, thermoregulatory, metabolic, circadian and stress responses. However, the cellular mechanisms underlying these multifunctional roles remain poorly understood. Neurones from the PVN project to and can alter the function of sympathetic control regions in the medulla and spinal cord. Dysfunction of sympathetic pre-autonomic neurones (typically hyperactivity) is linked to several diseases including hypertension and heart failure and targeting this region with specific pharmacological or biological agents is a promising area of medical research. However, to facilitate future medical exploitation of the PVN, more detailed models of its neuronal control are required; populated by a greater compliment of constituent ion channels. Whilst the cytoarchitecture, projections and neurotransmitters present in the PVN are reasonably well documented, there have been fewer studies on the expression and interplay of ion channels. In this review we bring together an up to date analysis of PVN ion channel studies and discuss how these channels may interact to control, in particular, the activity of the sympathetic system.

Keywords: PVN, paraventricular nucleus, hypothalamus, ion channels, hypertension

\section{INTRODUCTION}

\section{Location and Cytoarchitecture}

The paraventricular nucleus of the hypothalamus (PVN) is one of the most important autonomic control centers in the brain with roles in a number of homeostatic responses (Badoer, 2001; Coote, 2007; Pyner, 2009; Nunn et al., 2011). In the rat, the PVN extends rostrocaudally below the third ventricle and is the most dorsal component of the thalamic midline-intralaminar nuclear complex (Paxinos and Watson, 1986). In both rodents and primates, neurones in the PVN connect extensively with a variety of neurones in the hypothalamus, brainstem, limbic regions and prefrontal cortex (Swanson et al., 1980; Swanson and Sawchenko, 1983). 
The PVN comprises of several anatomical subdivisions, with the region typically divided into parvocellular and magnocellular subnuclei. The rat parvocellular area includes approximately 1000 small neurones that project to regions in the central nervous system (CNS) involved in autonomic control (Swanson and Kuypers, 1980; Lovick et al., 1993; Shafton et al., 1998; Pyner and Coote, 2000) via projections to the spinal cord (termed spinally projecting neurones) and medulla (Swanson and Kuypers, 1980; Hosoya et al., 1991; Shafton et al., 1998; Pyner and Coote, 2000). The magnocellular area contains larger neurones that project to the posterior pituitary. Cells within this area typically have a neuroendocrine function, for example, secretion of vasopressin and oxytocin. To date, 30 or more neurotransmitters have been identified in this region (Pyner, 2009). The parvocellular and magnocellular regions can be further subdivided (Figure 1A); although an alternative approach to anatomical subdivisions can be seen in Figures 1B,C. Here, the PVN is divided more loosely into the parvocellular area, posterior magnocellular lateral area and the intermediocellular region (dorsal and caudal PVN) where pre-autonomic neurones are most abundant (Kiss et al., 1991; Chen et al., 2014).

Much of the earliest anatomical information on these subnuclei originated from detailed studies in rats (Swanson et al., 1980; Swanson and Sawchenko, 1983; Simmons and Swanson, 2008). However, the mouse PVN has been described as an equally complex in structure, but with noticeable differences. Unlike the rat PVN (Swanson and Kuypers, 1980), the mouse PVN is not as well differentiated and magnocellular and parvocellular neurones are often indistinguishable (Biag et al., 2012). In contrast to numerous studies on the rat PVN, few studies have compared neuropeptide distribution in the mouse PVN (Castel and Morris, 1988; Shimada and Ishikawa, 1989; Broberger et al., 1999; Kadar et al., 2010).

\section{Functional Roles of the PVN}

The broad range of PVN roles in physiological integration have been reviewed extensively (Swanson and Sawchenko, 1980; Baertschi et al., 1983; Ferguson et al., 2008), including influence over the sympathetic nervous system and have been implicated in the control of cardiovascular function for example, regulating the cardiac sympathetic afferent reflex (Zhong et al., 2008), regulation of blood volume (Lovick et al., 1993; Pyner and Coote, 2000), circadian regulation of blood pressure (Cui et al., 2001) and cardiovascular responses to stress (Jansen et al., 1995). Pharmacological or electrical stimulation of the PVN results in rapid rises in heart rate, blood pressure and renal sympathetic nerve activity (Martin et al., 1991; Kannan et al., 1989; Martin and Haywood, 1993; Duan et al., 1997; Zhang et al., 1997; Schlenker et al., 2001; Kawabe et al., 2009). There has been some controversy regarding whether pre-autonomic PVN neurones really are involved in the cardiovascular response to stress; with Dampney and others (Dampney, 1994; DiMicco et al., 1995; Fontes et al., 2001; DiMicco et al., 2002) ascribing this to a mis-classification of dorsomedial hypothalamic action, but as we discussed previously (Nunn et al., 2011), the consensus does seem that these neurones are "multi-functional." The physiological role of the PVN extends further than control of cardiovascular function; the PVN has multiple diverse roles such as hormonal stress responses, circadian rhythm and thermoregulation (see Nunn et al., 2011 for a review). In addition to altering changes in blood pressure, spinally projecting PVN neurones are thought to play a role in blood volume regulation (Lovick and Coote, 1988, 1989; Lovick et al., 1993). For example, stimulation of atrial stretch receptors resulted in inhibition of renal sympathetic nerve activity and increased c-fos expression in the parvocellular PVN (Pyner et al., 2002). Furthermore, targeted injections at different sites within the PVN, mainly located in the dorsal parvocellular region, led to an increase in renal sympathetic nerve activity, which was reversed by reducing the injection volume (Deering and Coote, 2000). In addition, the PVN is thought to be involved in the control of energy balance through its influences on feeding, pituitary hormone secretion and the autonomic nervous system. In rats, stimulation of the PVN resulted in an increase in interscapular brown adipose tissue (BAT) temperature (Amir, 1990). This response could be inhibited by the sympathetic ganglionic blocker chlorisondamine, chloride or the $\beta$-adrenergic receptor antagonist, propranolol but not by hypophysectomy, indicating the involvement of the sympathetic nervous system. In a later study, injection of the gut hormone cholecystokinin (CCK), known to reduce food intake, into the third ventricle resulted in an increase in firing rate of sympathetic nerves to BAT (Yoshimatsu et al., 1993). A more recent study has illustrated that orexigenic neuropeptide Y (NPY)-containing neurones of the arcuate nucleus (Arc) control BAT thermogenesis and sympathetic outflow via tyrosine hydroxylase (TH) PVN neurones (Shi et al., 2013). Additional studies involving lesioning or injecting various peptides into the PVN have resulted in overeating/obesity or reduced eating/anorexia, suggesting the PVN is also involved in food intake (Leibowitz et al., 2007).

The PVN has important regulatory functions for hepatic glucose control, a subject that has been elegantly reviewed by O'Hare and Zsombok (2016). Retrograde neuronal tracing studies show that PVN projections directly innervate the liver through both the sympathetic and parasympathetic systems (la Fleur et al., 2000; Buijs et al., 2003; Kalsbeek et al., 2004). In several studies, some liver-related PVN neurones have been shown to express oxytocin and corticotrophin-releasing hormone, but not vasopressin (Buijs et al., 2003; Stanley et al., 2010).

The role of the PVN in the stress response has been well documented. Duan et al. (1997) showed that cardiovascular responses to stress can be mimicked by electrical stimulation of the PVN (Duan et al., 1997). In addition, parvocellular preautonomic neurones expressing tachykinin receptors have been implicated in having a role in the stress response (Herman and Cullinan, 1997) and work from our group has shown that the tachykinin, substance $\mathrm{P}$ (SP), activates spinally projecting neurones during electrophysiological recordings (Womack and Barrett-Jolley, 2007; Womack et al., 2007). The PVN is the main driver of hypothalamic-pituitary adrenal (HPA) responses and is controlled by peptidergic neuroendocrine neurones located in the medial parvocellular division (Herman and Cullinan, 


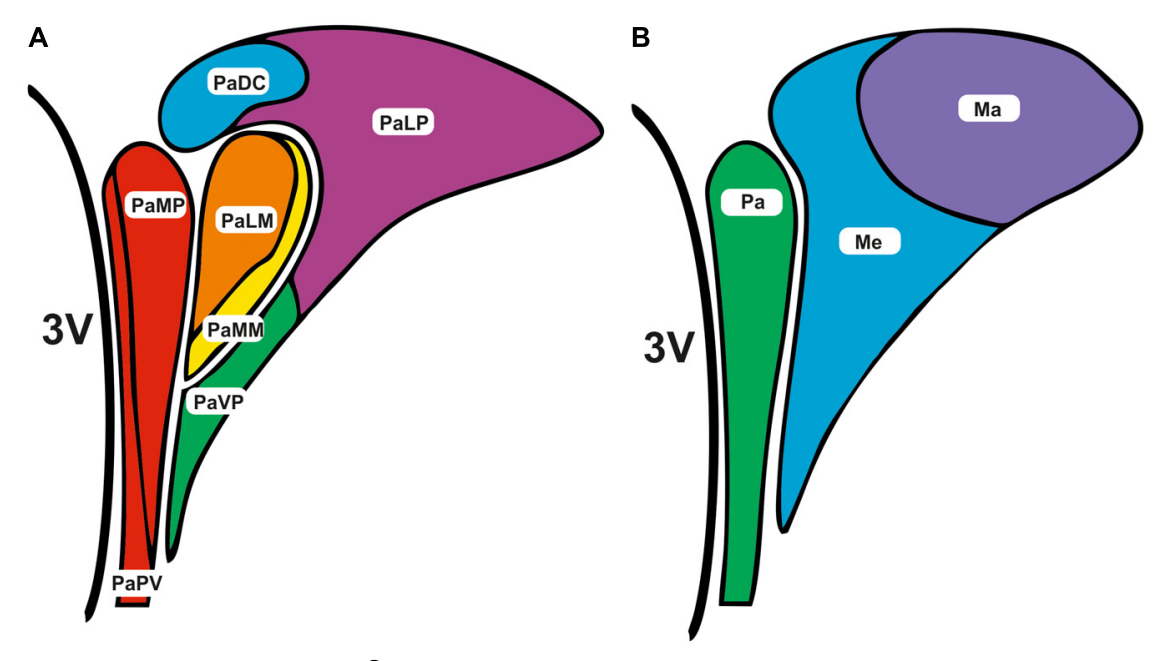

C

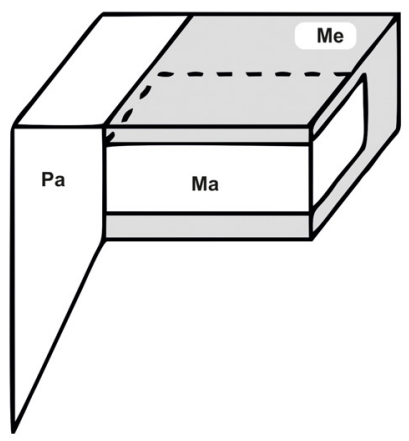

FIGURE 1 | Subdivisions of the paraventricular nucleus. The subdivisions of the PVN are adjacent to the third ventricle (3V). (A) Parvocellular and magnocellular regions are further subdivided into the following areas; lateral magnocellular (PaLM), medial magnocellular (PaMM), medial parvocellular (PaMP), lateral parvocellular (PaLP), periventricular subnucleus (PaPV), medial ventral parvocellular (PaVP), and dorsal cap (PaDC) (Paxinos and Watson, 1986; Koutcherov et al., 2000).

(B,C) Alternatively the PVN can be divided more loosely into the parvocellular (Pa), posterior magnocellular lateral (Ma), and the intermediocellular regions (Me) (Kiss et al., 1991; Chen et al., 2014).

1997; Myers et al., 2012; Flak et al., 2014). Chronic stress has been shown to induce neuronal plasticity by methods including activation of glutamatergic innervations of parvocellular PVN CRH neurones (Flak et al., 2009).

The suprachiasmatic nucleus of the hypothalamus (SCN) is the primary circadian pacemaker in mammals and sends both inhibitory and excitatory projections throughout the PVN (Hermes et al., 1996a,b; Kalsbeek et al., 2000; Cui et al., 2001). Bilateral injections of bicuculline into the PVN prevents lightinduced inhibition of melatonin; this study concluded that the GABAergic projections from the SCN were responsible for regulating melatonin release (Kalsbeek et al., 2000). Furthermore, lesioning the PVN results in a lower night-time level of melatonin (Kalsbeek et al., 2000).

The PVN plays a role in osmoregulation. For historical context, the earliest electrophysiology on hypothalamic osmosensing showed that SON neurones are excited by increases in tonicity and hyperpolarized and inhibited by hypotonicity (Mason, 1980). Following this, Yamashita et al. (1984) included a temperature and osmolality study in an extensive PVN neuropharmacological program (Yamashita et al., 1984), proposing that only about $10 \%$ PVN neurones were inhibited by osmolality (i.e., excited by hypertonicity) with about 35\% behaving in the opposite way. There are emerging links between hypothalamic osmolality and sympathetic activity in addition to the established hypothalamic-neurohypophesis pathway. For example, hypertonic saline injected into the hypothalamus yields a pressor response (Chen and Toney, 2001; Bourque, 2008; Chu et al., 2010) and hypotonicity decreases sympathetic nerve activity, blood pressure and heart rate (Bourque and Oliet, 1997). Toney and co-workers propose that these mechansisms serve to support blood pressure and heart rate in the face of dehydration (Holbein et al., 2014).

The PVN also has roles in thermoregulation; Inenaga et al. (1987) were the first group to show the presence of thermosensitive neurones in the PVN and there have since been several studies demonstrating a role for the PVN in thermoregulation and thermogenesis (Cham et al., 2006; Cham and Badoer, 2008; Chen et al., 2008; Leite et al., 2012). Polysynaptic tracing using the pseudorabies virus in rats identified spinally projecting neurones of the PVN specifically as being directly involved in thermoregulation (Leite et al., 2012). 


\section{Electrophysiological Phenotypes of PVN Neurones}

The electrophysiological properties of neurones within the PVN have been characterized in several studies. Early work used patch-clamp electrophysiology to record the electrical properties of hypothalamic neurones and labeled cells by injecting Lucifer yellow, ethidium bromide or biocytin (Hoffman et al., 1991). Further work by this group and others described three distinct types of PVN neurones based on their electrophysiological properties and these classifications are still useful today (see for example Lee et al., 2012). Type I neurones were identified as neurosecretory magnocellular neurones with phasic bursting patterns, expressing a rapidly inactivated, or "A-type," potassium conductance (Tasker and Dudek, 1993; Sonner and Stern, 2005). Type II (parvocellular) neurones express a slowly inactivating delayed rectifier potassium conductance. The differences between types I and II cells may be explained by differential expression of voltage-gated potassium and calcium channels (Luther and Tasker, 2000). Furthermore, Tasker and Dudek (1991) described two different neuronal phenotypes within the parvocellular area; (1) exhibiting electrophysiological properties similar to neuroendocrine magnocellular cells and (2) pre-autonomic neurones (Tasker and Dudek, 1991). In the parvocellular subnuclei, medullaprojecting neurones show strong inward rectification and "A-type" potassium conductance (Stern, 2001; Sonner and Stern, 2005) whereas spinally projecting neurones show a slowly inactivating potassium conductance (Barrett-Jolley et al., 2000).

Ion channel expression is the key determinant of neuronal function; to model, understand and exploit the therapeutic potential of the PVN it will be necessary to establish which ion channels are present in the first place. Sonner et al. (2011) have already shown that disruption of ion channel regulation at the level of the PVN can lead to increased neuronal excitability of pre-sympathetic neurones, potentially contributing to sympathetic over activity (Sonner et al., 2011). Furthermore, the remarkable recent work of Geraldes et al. (2014, 2016, 2018) (discussed later) highlight the rich diversity of ways in which this could be exploited in the future.

\section{Ion Channels of the PVN}

An ion channel is a pore-forming protein found on a cell membrane that permits the transport of ions, for example potassium, sodium and/or calcium. The main roles of ion channels include, but are not limited to, setting the resting membrane potential, shaping the action potential, transmitting electrical signals and acting as biological sensors (Clapham, 2003). As discussed above, the PVN has multiple, diverse roles resulting from neurone-to-neurone communication and propagation of electrical impulses from other areas of the brain. Excitability of PVN neurones results from the properties and distribution of ion channels on the plasma membrane, therefore, it is likely that any modification in ion channel function/distribution may affect the integration and propagation of such electrical signals.

\section{AMINO ACID RECEPTOR CHANNELS}

Probably the earliest identified and best studied ion channels in the PVN are GABA and glutamate receptors (Table 1). This is unsurprising as GABA and glutamate are the most widely distributed inhibitory and excitatory neurotransmitters in the brain, respectively. Inputs to the PVN arise from the "timekeeper" SCN via glutaminergic input (Cui et al., 2001). The PVN is kept tonically inactive through the activity of surrounding GABA neurones (Martin and Haywood, 1992, 1993). Indirect inhibition of GABA is one mechanism by which several agents modulate pre-sympathetic neurones; nitric oxide (NO) (Li et al., 2002, 2004a), angiotensin (Li et al., 2003) and substance P (SP) act on GABA neurones in this way (Figure 2) (Womack et al., 2007).

$\mathrm{GABA}_{\mathrm{A}}$ receptor whole-cell (Womack et al., 2006) currents, single channel activity (Barrett-Jolley, 2001) and gene expression have all been characterized throughout the PVN in a number of studies. For example, Cullinan (2000) detected mRNA of $\alpha 2, \beta 1$, and $\beta 3$ subunits in $>94 \%$ of CRH neurons and $\alpha 1$ and $\beta 3$ subunits detected in $>53 \%$ and $>65 \%$ of $\mathrm{CRH}$ neurones, respectively. In addition, mRNA levels of the GABA $\alpha_{1}$ receptor types were shown in the PVN (Wang et al., 2009). Wang et al. (2009) also explored functional roles of GABA receptors in the PVN; injection of the GABA $\alpha$ receptor agonist muscimol or the $\mathrm{GABA}_{\beta}$ receptor agonist baclofen into the PVN resulted in similar, dosedependent reductions in heart rate, mean arterial pressure and renal sympathetic activity (Wang et al., 2009).

In situ hybridization and immunohistochemical analyses confirmed the existence of the GluR5 kainate subunit in the PVN. Intra-PVN infusion of the kainate antagonist LY382884 increased plasma adrenocorticotropin (ACTH), corticosterone and PVN c-fos immunoreactivity (Evanson et al., 2009). We discuss the "energy sensing" $\mathrm{K}_{\text {ATP }}$ channel later, but PVN GABAneurotransmission is also critical for metabolic regulation, where alterations at the level of the PVN contribute to dysregulation of hepatic functions including glucose metabolism. Administration of the glutamate agonist N-methyl-d-aspartate (NMDA) and the $\mathrm{GABA}_{\mathrm{A}}$ antagonist bicuculline into the PVN significantly increased plasma glucose and glucagon levels, without change in plasma insulin. Interestingly, this response was absent in rats following sympathectomy (Kalsbeek et al., 2004).

\section{TRANSIENT RECEPTOR POTENTIAL CHANNELS}

The parvocellular PVN, above everything else, is an integration center, receiving inputs from a number of sources to modulate sympathetic output. These include synaptic inputs from the SCN, an area of the hypothalamus controlling circadian rhythm and the cardiovascular autonomic control centers (Nunn et al., 2011). The PVN also plays a role in sensing changes in temperature, glucose, osmolality and other homeostatic processes (Cham and Badoer, 2008; Melnick et al., 2011; Feetham and Barrett-Jolley, 2014; Feetham et al., 2015b). Therefore, it is likely that this region is richly populated with ion channels which we hypothesize act as biological sensors (Clapham, 2003), such as the transient receptor 
TABLE 1 | Amino acid receptor channels in the PVN.

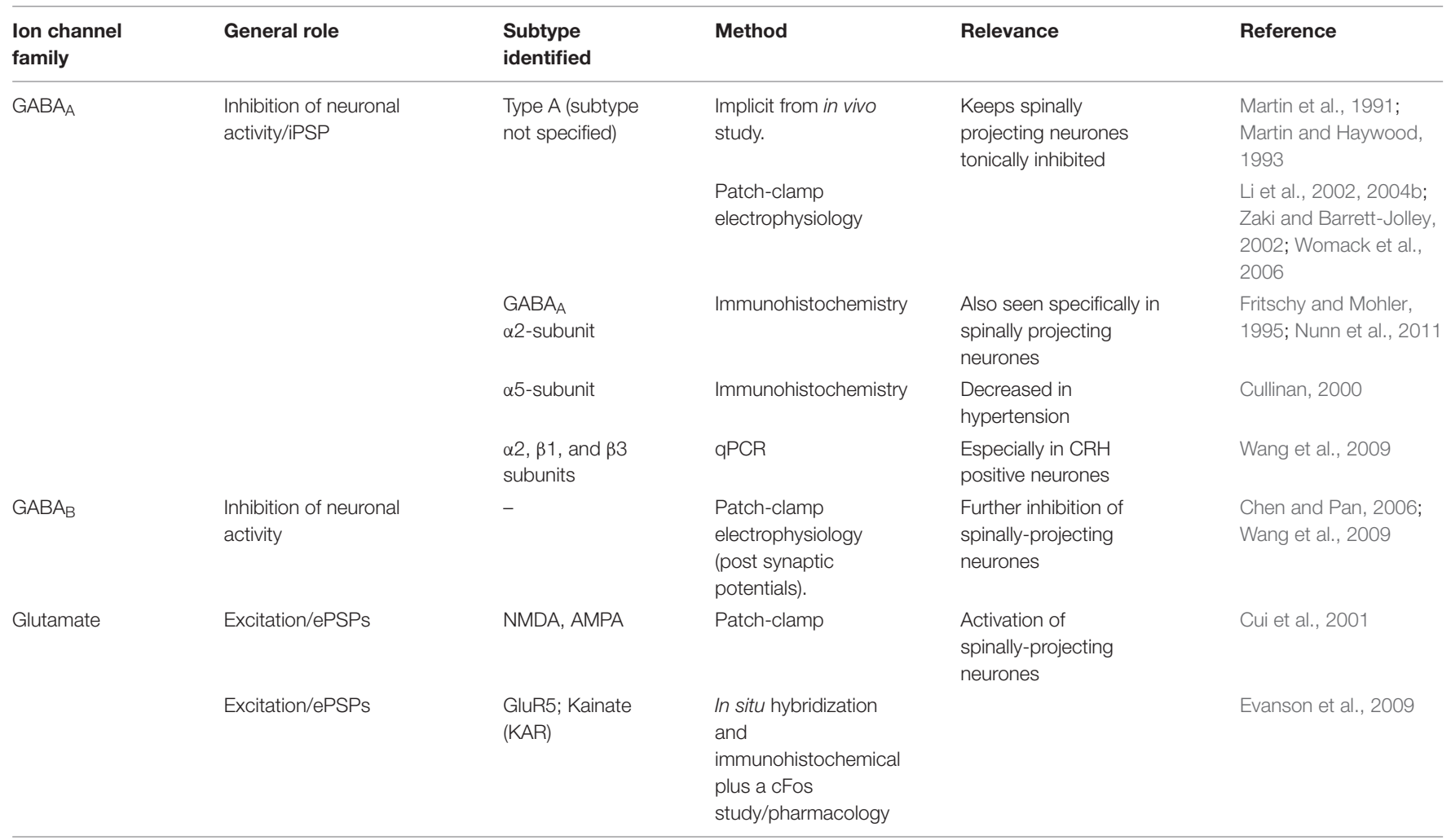

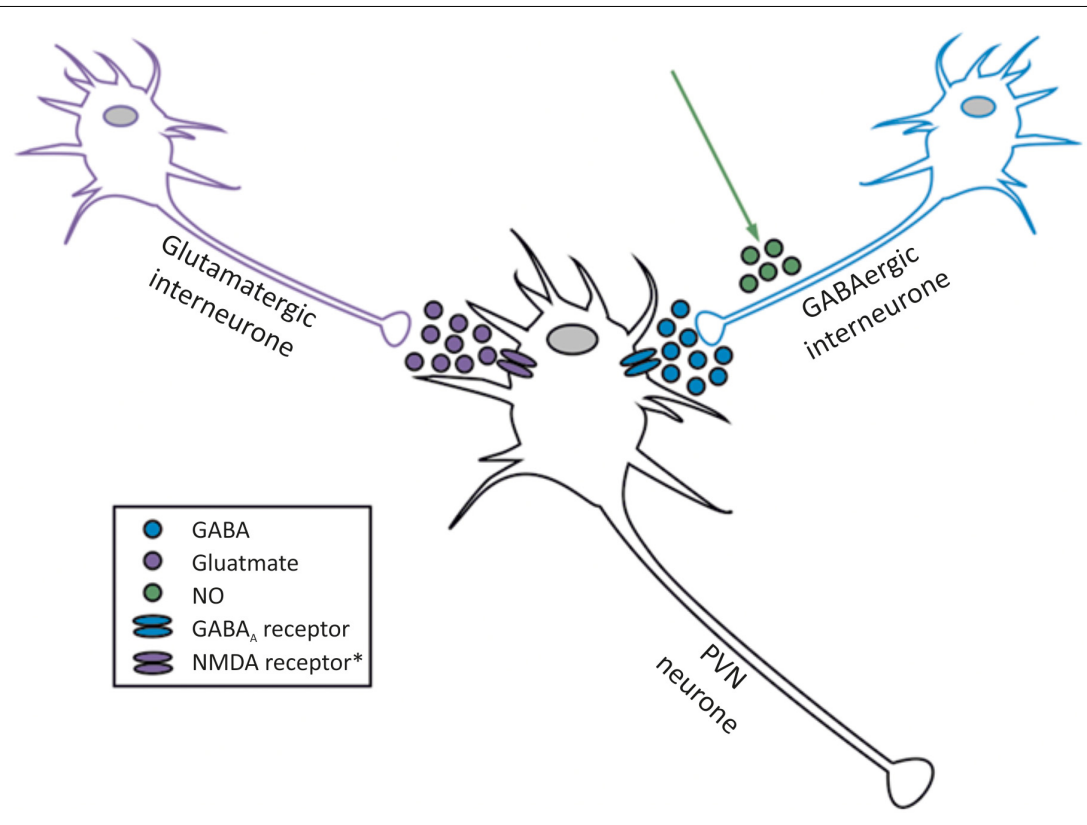

FIGURE 2 | Interaction between glutamate, GABA and NO acting on neurones within the PVN. The two best established inputs to PVN spinally projecting neurones are GABA (inhibitory) and glutamate (excitatory), but NO is one of several factors that amplifies the GABA input. Spinally projecting sympathetic neurones are influenced by NO, but do not produce it themselves (Watkins et al., 2009). *NMDA, kainate and AMPA receptors have been identified in the PVN, please see full text.

potential (TRP) ion channels. The TRP multigene superfamily encodes a family of 28 ion channels that are conserved in yeast, invertebrates and vertebrates. The TRP family is divided into seven subfamilies, TRPC (canonical; seven members), TRPV (vanilloid; six members), TRPA (ankyrin; 1 member), TRPM (melastatin; eight members), TRPML (mucolipin; 1 member), 
TRPP (polycystin; two members) and TRPN (NOMPC; only seen so far in non-mammals) (Li et al., 2006). The majority of TRPs are termed non-selective cation channels, although most have greater selectivity for $\mathrm{Ca}^{2+}$ ions than monovalent cations. The TRP family has multiple biological roles as key molecular sensors both inside and outside the CNS and channel activation can vary from ligand binding to voltage, chemical, physical or thermal challenge. Since TRP channels usually have equal selectivity for both $\mathrm{Na}^{+}$and $\mathrm{K}^{+}$ions it would typically suggest that TRP channel activation would depolarize the cell membrane and activate voltage-dependent ion channels. However, both our experimental and modeling data show that TRP activation increases intracellular $\mathrm{Ca}^{2+}$ concentration and results in secondary activation of $\mathrm{Ca}^{2+}$-activated potassium channels (see TRPV4 below) and membrane hyperpolarization (Feetham et al., 2015b).

Several TRP channels have been identified in the PVN (Table 2). Interestingly, patch-clamp electrophysiology on parvocellular PVN neurones shows that angiotensin II, in addition to its modulation of GABA-ergic neurotransmission as discussed earlier, also results in cell depolarization through the modulation of non-selective cationic and potassium conductances in rats (Latchford and Ferguson, 2005). It is plausible that this non-selective cation conductance is mediated by TRP channels and that they can act as signals downstream of receptor activation in the PVN. In another study, leptin was found to increase a non-selective cation conductance and depolarize both type I and II PVN neurones, suggesting that neurones in the PVN are involved in the physiological response to leptin via non-selective cationconductances (Powis et al., 1998). Although the identity of the specific ion channels responsible is still unknown, there is evidence to suggest that TRP channels may be involved. For example, a study investigating the effect of leptin on PVN mediated sympathetic output (Zheng et al., 2014) found that sympathetic activity was almost abolished by the TRPC inhibitors 2APB and SKF96365. However, it is worth noting that a caveat with any pharmacological inhibition of TRP channels is that the modulators are often not as selective as one would hope.

\section{TRPC (Canonical Transient Receptor Potential) Channels}

The TRPCs are extensively expressed in the brain (Li et al., 1999) but also expressed in other organs for example, the heart, kidneys and the lungs. Of the seven TRPC channel members identified, TRPC4 is the predominant subtype in the rat brain (Fowler et al., 2007). TRPCs have been identified in the PVN using a variety of techniques; for example, TRPC4 and TRPC5 mRNA were detected using in situ hybridization (Fowler et al., 2007). In addition, microarray analysis also confirmed the presence of TRPC4 in the PVN (Hindmarch et al., 2006). This study also aimed to investigate the role of TRPC4 in the PVN with TRPC4 expression increased following water deprivation (Hindmarch et al., 2006). This "transcriptomic" study suggests that TRPC4 may be differentially expressed as a part of an adaptive response to hyper-osmolality. However, the size of the effect, specifically in the PVN, is unclear since more recent qPCR data shows a large increase in SON TRPC4 mRNA in water deprivation (whole tissue homogenates), but little change in the PVN itself (Nedungadi and Cunningham, 2014). We subsequently have shown that TRPV4 has a central role in osmoregulation in the PVN using patch clamp electrophysiology, however, it is likely that other channels, such as TRPC channels may also be involved (Feetham et al., 2015b).

TABLE 2 | TRP channels in the PVN.

\begin{tabular}{|c|c|c|c|c|c|}
\hline $\begin{array}{l}\text { Ion channel } \\
\text { family }\end{array}$ & General role & $\begin{array}{l}\text { Subtype } \\
\text { identified }\end{array}$ & Method & Relevance & Reference \\
\hline $\begin{array}{l}\text { TRPC } \\
\text { Canonical } \\
\text { Store-operated }\end{array}$ & $\begin{array}{l}\text { Calcium } \\
\text { homeostasis, open } \\
\text { with } \downarrow \mathrm{Ca}^{2+}\end{array}$ & $\begin{array}{l}\text { TRPC4 } \\
\text { TRPC1-6 } \\
\text { TRPC }\end{array}$ & $\begin{array}{l}\text { RT-PCR, } \\
\text { western blot } \\
\text { RT-PCR } \\
\text { Patch-clamp } \\
\text { electrophysiology }\end{array}$ & $\begin{array}{l}\text { Expression increased following } \\
\text { water deprivation } \uparrow \\
\text { Expression contributes to } \\
\text { inappropriate vasopressin } \\
\text { release in cirrhosis. }\end{array}$ & $\begin{array}{l}\text { Hindmarch et al., 2006; } \\
\text { Fowler et al., 2007; } \\
\text { Zheng et al., } 2014\end{array}$ \\
\hline $\begin{array}{l}\text { TRPV } \\
\text { Vanilloid }\end{array}$ & $\begin{array}{l}\text { Mechanosensitive } \\
\text { and homeostatic } \\
\text { roles }\end{array}$ & $\begin{array}{l}\text { TRPV1 } \\
\text { TRPV2 } \\
\text { TRPV4 }\end{array}$ & $\begin{array}{l}\text { Radiolabeling, } \\
\text { patch clamp } \\
\text { electrophysiology } \\
\text { Immunohistochemistry, } \\
\text { Western blot, } \\
\text { patch clamp } \\
\text { electrophysiology, } \\
\text { in vivo studies }\end{array}$ & $\begin{array}{l}\text { Activation leads to glutamate } \\
\text { release and postsynaptic firing. } \\
\text { Co-localized with liver-related } \\
\text { neurones } \\
\text { Regulates body fluid } \\
\text { homeostasis, autonomic } \\
\text { control and metabolism } \\
\text { Pharmacological activation of } \\
\text { TRPV4 } \downarrow \text { firing in brain slice, } \\
\text { depolarization and } \mathrm{Ca}^{2+} \text { rise in } \\
\text { isolated neurones. TRPV4 } \\
\text { inhibitors reverse hypotonic } \\
\text { effects on firing. }\end{array}$ & $\begin{array}{l}\text { Li et al., 2004b; } \\
\text { Roberts et al., 2004; } \\
\text { Carreno et al., 2009; } \\
\text { Zsombok et al., 2011; } \\
\text { Gao et al., 2012; } \\
\text { Nedungadi et al., 2012; } \\
\text { van den Burg et al., } \\
\text { 2015; Feetham et al., } \\
\text { 2015a }\end{array}$ \\
\hline $\begin{array}{l}\text { TRPM } \\
\text { Melastatin }\end{array}$ & $\begin{array}{l}\text { Sensor/homeostatic } \\
\text { roles, exhibit } \\
\text { temperature } \\
\text { sensing properties }\end{array}$ & $\begin{array}{l}\text { TRPM4 and } \\
\text { TRPM5 }\end{array}$ & $\begin{array}{l}\text { Confocal } \\
\text { immunofluorescence }\end{array}$ & $\begin{array}{l}\text { Differential expression } \\
\text { dependent upon area of } \\
\text { neurone }\end{array}$ & Teruyama et al., 2011 \\
\hline
\end{tabular}


Osmoregulation is not the only role for TRPCs in the PVN; they also appear to contribute to the elevated sympathetic activity seen in type 2 diabetes (T2D) (Zheng et al., 2014). PVN qPCR data show increased mRNA expression of several subtypes of TRPC channel (TRPC1, 4, 5, and 6) following streptozotocin induced T2D (see "PVN Ion Channels in Disease" section below). Parallel in vitro data suggest that this phenomenon results from the action of the energy regulating hormone leptin (Zheng et al., 2014) that is increased in diabetes (Pan et al., 2014).

\section{TRPV (Vanilloid Transient Receptor Potential) Channels}

In the periphery, TRPV channels are associated with pain, mechanosensation (Guilak et al., 2010) and thermoregulation (Caterina, 2007). The majority of studies on the functional/structural properties of TRPV channels in the CNS have focused on TRPV1. However, at least 5 other TRPV channels have been identified in mammals including TRPV2, TRPV3, and TRPV4, all of which are found in the CNS (Caterina, 2007). TRPV channels have been widely reported in the PVN; to summarize, TRPV1, TRPV2, TRPV4, and TRPV5 channel expression has been reported. A thorough autoradiography study using TRPV1 null mice as a negative control identified weak TRPV1 protein expression in the PVN of mice (Roberts et al., 2004). This is backed up by patch clamp brain slice data in rats, showing TRPV1 channel dependent activation of glutaminergic neurotransmission (Li et al., 2004b). Additionally, combined viral retrograde tracer and immunohistochemical data show TRPV1 expression in liver projecting pre-autonomic PVN neurones, and co-localization with insulin receptor 2 (Zsombok et al., 2011; Gao et al., 2012); suggesting that TRPV1 in the PVN appears to play a role in the control of hepatic glucose production. The hypothesis is that this PVN projection serves to couple liver glucose production with other physiological and endocrine PVN targets via increases of (liver) sympathetic activity. This, along with the TRPC data discussed above, demonstrates the striking potential of ion channel modulation at the level of the PVN to ameliorate sympathetic activity in a range of cardiovascular and metabolic disorders.

Immunohistochemical techniques in the rat brain have also identified TRPV2 in the magnocellular region of the PVN with some staining also observed in the posterior parvocellular region and dorsal horn (Nedungadi et al., 2012). This study also revealed co-localization of TRPV2 with vasopressin-expressing cells in the magnocellular PVN, further highlighting the complexity of TRP channel mediated osmoregulation in the PVN. A further role for TRPV2 has also been proposed in primary hypothalamic neurones; where oxytocin, one of the many PVN neuropeptide transmitters, has been shown to induce $\mathrm{Ca}^{2+}$ dependent signaling via activation of TRPV2 channels. One immunohistochemistry study revealed co-localization of TRPV2 and oxytocin in the PVN, suggesting that TRPV2 may be a mediator of the anxiolytic effects of oxytocin (van den Burg et al., 2015). Since oxytocin appears to have other roles too, it will be interesting to discover if they too are mediated by TRPV2. It is quite likely that in native tissue, combinations of different ion channels are involved with any given response and this is emphasized by similar data showing TRPV5 mediated oxytocin (and vasopressin) responses (Kumar et al., 2017). This TRPV5 expression study used immunohistochemistry and target verification with siRNA knock-down of the channel (Kumar et al., 2017). TRPV5 has been observed in both neurones and glia, although the role of TRPV5 in glia is yet to be established. This study showed TRPV5 expression in a remarkable $\sim 50 \%$ of vasopressin neurones and $\sim 6-7 \%$ of oxytocin neurones in the rat PVN (Kumar et al., 2017). It is therefore likely that TRPV2 and TRPV5 work in a coordinated fashion in the maintenance of endocrine homeostasis.

Western blot studies have shown that TRPV4 is also expressed in the PVN (Carreno et al., 2009). Our own group has confirmed the presence of TRPV4 in the PVN using immunohistochemistry and patch-clamp electrophysiology. Our data show that TRPV4 is involved in osmosensing in the PVN (Feetham et al., 2015a,b). We investigated the detailed mechanism of hypotonicity mediated decreases in parvocellular PVN neurones with a series of in vivo, in vitro and in silico studies (Feetham et al., 2015a,b). We found TRPV4 to be central to the PVN hypotonic response, but the mechanism underlying these responses involved a rise in intracellular $\mathrm{Ca}^{2+}$, which could possibly be missed with whole-cell patch clamp recordings. Our evidence was briefly as follows; following addition of TRPV4 agonists, a decrease in firing rate was observed similar to that seen during hypotonic challenge in the absense of TRPV4 activation. In addition, we reported that the decrease in firing with hypotonic challenge could be reversed with TRPV4 specific inhibitors. In whole-cell experiments, addition of TRPV4 activators led to the depolarization of isolated PVN neurones from rats, but an increase in intracellular $\mathrm{Ca}^{2+}$ was observed in intact cells (Feetham et al., 2015a). We created (Figure 3) and validated (Figure 4) this model numerically using a mathematical model written in NEURON and whilst less mechanistic, we verified that TRPV4 was involved with central osmosensing at the whole animal level in vivo experiments; central injections of hypotonic solution decreased blood pressure and this effect was blocked by a TRPV4 inhibitor (Feetham et al., 2015a).

\section{TRPM (Melastatin Transient Receptor Potential) Channels}

Of this family, the best characterized channels in the PVN are TRPM4 and M5 (Teruyama et al., 2011). These are closely related channels with $40 \%$ amino acid sequence homology and are rather distinct from most other TRP channels (including the other melastatin TRPs) in that they are $\mathrm{Ca}^{2+}$ impermeant (Liman, 2014). Both these channels are of relatively low conductance [in the order of 20pS (Nilius et al., 2003; Zhang et al., 2007)] and TRPM5 is a well-established chemical sensor. TRPM5 is best characterized for gut chemosensing and for sensing bitter, sweet and umami in gustatory neurones (Perez et al., 2002). It seems reasonable to speculate that TRPM4 and TRPM5 in the PVN may therefore serve as sensors, extending the integrative capacity of the PVN to chemical sensing. TRPM4 channels are sensitive to $\mathrm{pH}$ and reactive oxygen species and intracellular ATP levels 
A

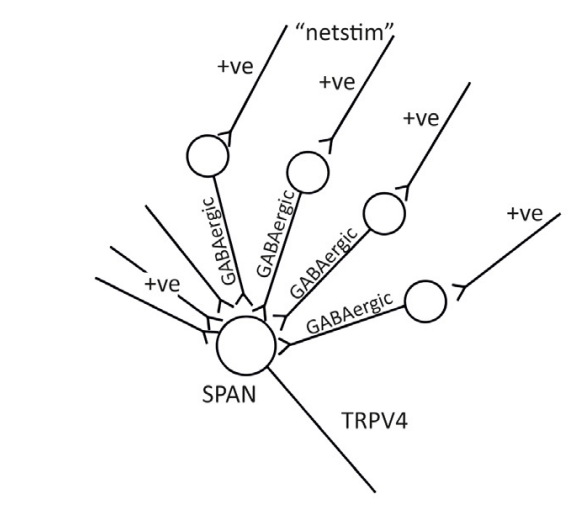

E

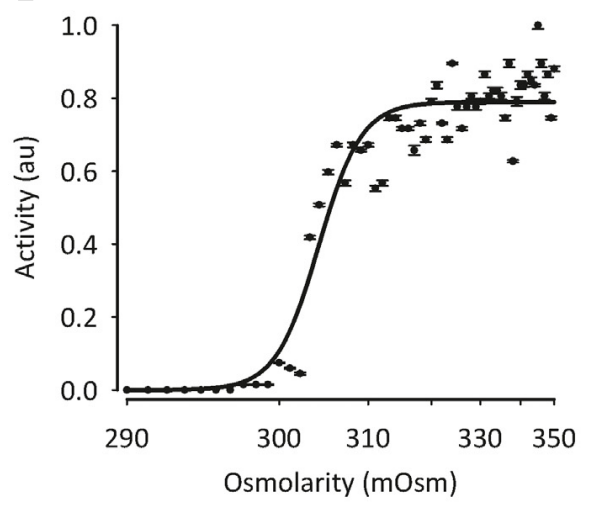

B

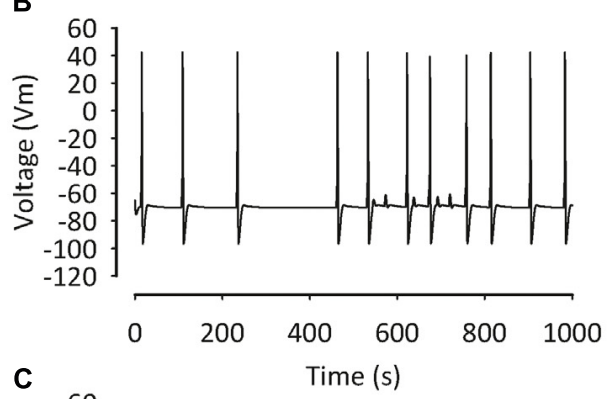

C
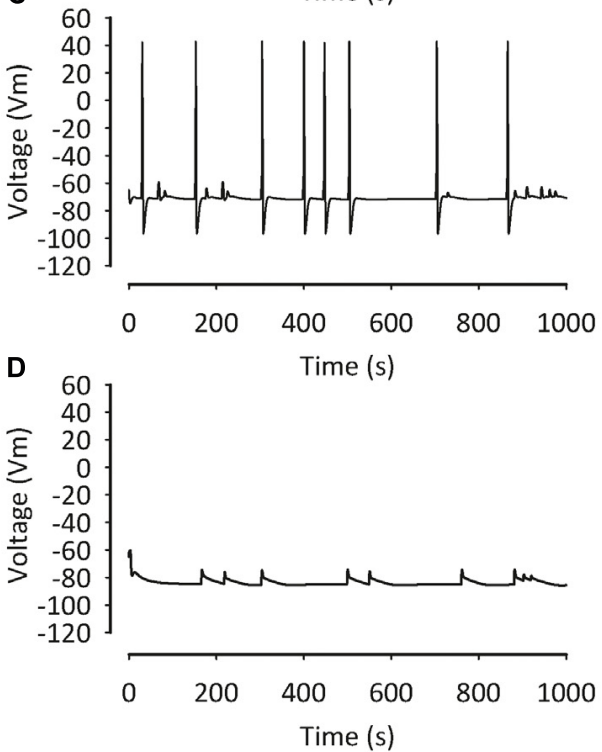

FIGURE 3 | Mathematical model of pre-autonomic neurone regulation by osmolality. To test the plausibility of our PVN osmolality conceptual model, we deployed a mathematical model written in NEURON (Feetham et al., 2015b), including intracellular $\mathrm{Ca}^{2+}$ buffering. TRP channels were constructed as relatively non-specific cation channels with ratio $\left(\mathrm{Ca}^{2+}: \mathrm{K}^{+}: \mathrm{Na}^{+}\right)$6:1:1 and activated by hypotonicity. (A) Sympathetic pre-autonomic neurones (SPANS) receive excitatory and inhibitory input. Despite the activation of a non-specific cation channel conductance action potential frequency decreased (B) $320 \mathrm{mOsm}$, (C) $300 \mathrm{mOsm}$ (D) $280 \mathrm{mOsm}$. Data summarized in (E). Figure from Feetham et al. (2015b) with permission of the copyright holder John Wiley \& Sons, Inc.

(Mathar et al., 2014). It is therefore possible that they contribute to the changes in activity of the PVN seen with inflammaging (Zubcevic et al., 2011). However, thus far they have only been identified by confocal immunofluorescence in magnocellular regions (Teruyama et al., 2011), and not the parvocellular subnuclei directly associated with sympathetic control.

\section{POTASSIUM CHANNELS}

$\mathrm{K}^{+}$channels are the most widely distributed ion channel and are found in virtually all living organisms. They have a multitude of physiological functions making them common therapeutic targets (Humphries and Dart, 2015). Encoded by KCN genes, $\mathrm{K}^{+}$ channels form membrane spanning pores that are selective for $\mathrm{K}^{+}$ions (Alexander et al., 2015). Many subfamilies exist and are named from the physiological signals by which the pore opening is affected, for example, voltage and $\mathrm{Ca}^{2+}$-gated channels. Based on structure and function, $\mathrm{K}^{+}$channels generally have three major classes: the voltage-gated $\mathrm{K}_{\mathrm{v}}$ (including KCNA) with six transmembrane domains, inward rectifying, Kir (including KCNJ) with 2 transmembrane domains and the KCNK tandem pore domain (K2P) with 4 transmembrane domains.

\section{Voltage-Gated Potassium Channels}

$\mathrm{K}_{\mathrm{V}}$ channels open and close in response to changes in membrane potential, allowing passive flow of $\mathrm{K}^{+}$from the cell to restore membrane potential. They are key players in propagating electrical impulses in nerves as originally quantified by Hodgkin and Huxley (1952). The $\mathrm{K}_{\mathrm{v}}$ family includes some 40 voltage-gated potassium channel genes including KCNA which encodes the $K_{v} \cdot 1 x$ channels (Coetzee et al., 1999). Several $K_{v}$ channel subtypes have been identified in the PVN (Table 3), and the differences in electrophysiological properties of PVN neurones may be due to differences in $\mathrm{K}_{\mathrm{v}}$ expression levels. For example, immunohistochemical evidence has suggested that the "A-type" potassium current from PVN-RVLM neurones is mediated by KCNA4 $\left(\mathrm{K}_{\mathrm{v}} 1.4\right)$ and/or $\mathrm{KCND} 3\left(\mathrm{~K}_{\mathrm{v}} 4.3\right)$ channel subunits (Sonner and Stern, 2007). In contrast, the $K_{v}$ currents observed in identified spinally projecting neurones appeared to 


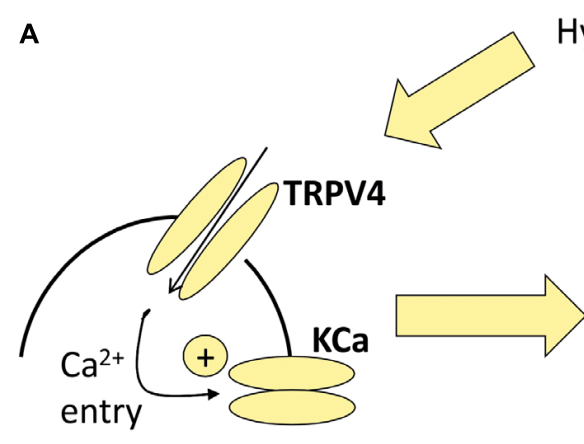

Hypotonic saline

Decrease in action potential frequency

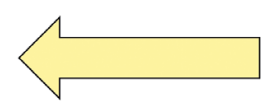

hyperpolarisation

\section{B}

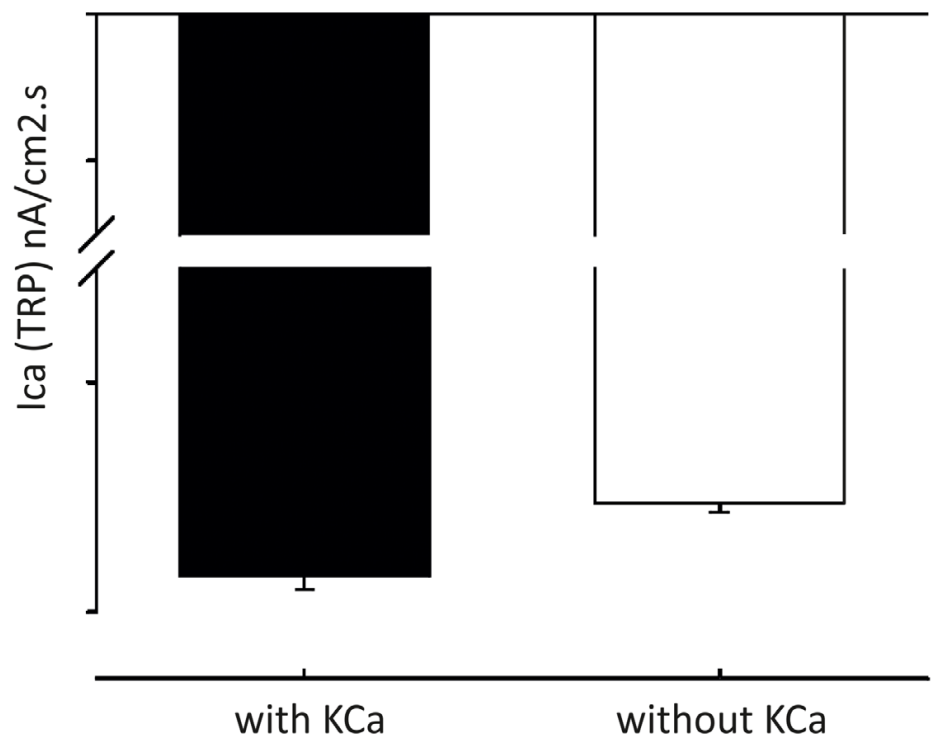

FIGURE 4 | Model of pre-autonomic neurone regulation by osmolality. From detailed analysis of the model (in Figure 3) we predicted that inward TRP dependent Ca currents would be increased in the presence of $\mathrm{K}_{\mathrm{Ca}}$ block (A); and we then validated this by experiment (B) Figure from Feetham et al. (2015b) with permission of the copyright holder John Wiley \& Sons, Inc.

be delayed rectifier in nature with no "A-type" potassium current observed (Barrett-Jolley et al., 2000). Further subtypes of voltagegated potassium channels have also been identified within rat PVN neurones. In a study using a combination of patchclamp electrophysiology and single cell reverse-transcriptase polymerase chain reaction (RT-PCR) in PVN neurones in rats, expression profiles of KCNA2 $\left(\mathrm{K}_{\mathrm{v}} 1.2\right)$, KCNA3 $\left(\mathrm{K}_{\mathrm{v}} 1.3\right)$, KCNA4 $\left(\mathrm{K}_{\mathrm{v}} 1.4\right)$, KCND1 $\left(\mathrm{K}_{\mathrm{v}} 4.1\right), \mathrm{KCND} 2\left(\mathrm{~K}_{\mathrm{v}} 4.2\right)$, and $\mathrm{KCND} 3\left(\mathrm{~K}_{\mathrm{v}} 4.3\right)$ in both types of neurones were identified, with some level of co-expression. KCND2 $\left(\mathrm{K}_{\mathrm{v}} 4.2\right)$ and $\mathrm{KCND} 3\left(\mathrm{~K}_{\mathrm{V}} 4.3\right)$ expression was shown to be higher in type I neurones, making it possible to distinguish between PVN cell types (Lee et al., 2012). The presence of KCNA2 $\left(\mathrm{K}_{\mathrm{V}} 1.2\right)$ has also been identified within rat PVN neurones using immunohistochemistry, with researchers reporting an increase in PVN KCNA2 $\left(\mathrm{K}_{\mathrm{V}} 1.2\right)$ expression following focal ischemic injury (Chung et al., 2001). Intuitively, increased expression of potassium channels may reduce firing rate and so may be a self-protective mechanism. In addition, KCNA2 $\left(\mathrm{K}_{\mathrm{V}} 1.2\right)$ along with KCNA1 $\left(\mathrm{K}_{\mathrm{V}} 1.1\right)$ channels have been shown to be downstream effectors of $\mathrm{NO}$ on synaptic GABA release to identified spinally projecting neurones of the rat PVN (Yang et al., 2007). 
The M-current is a slowly developing, non-inactivating, timeand voltage-dependent potassium current that was initially described in bullfrog sympathetic ganglia (Jones, 1987). It helps maintain the resting membrane potential of neurones and is mediated by KCNQ2 ( $\left.\mathrm{K}_{\mathrm{v}} 7.2\right)$ and KCNQ3 ( $\left.\mathrm{K}_{\mathrm{v}} 7.3\right)$ subunits (Coetzee et al., 1999). The PVN is rich in SP and interestingly, one of the first known modulators of the M-current was SP (Stanfield et al., 1985; Stonehouse et al., 1999), although this mechanism has not yet been characterized in the PVN. However, in a recent study, KCNQ2 ( $\left.\mathrm{K}_{\mathrm{v}} 7.2\right)$ and KCNQ3 $\left(\mathrm{K}_{\mathrm{v}} 7.3\right)$ have been identified specifically in CRH-expressing neurones within the PVN (Zhou et al., 2017). In this study, acute stress decreased KCNQ3 ( $\left.\mathrm{K}_{\mathrm{v}} 7.3\right)$ expression in the PVN of rats and blunted the excitatory effect of the KCNQ $\left(\mathrm{K}_{\mathrm{v}} 7\right)$ channel blocker, XE-991, on firing activity. These data suggest that acute stress-caused hyperactivity of the
HPA axis is due to a dysfunction of KCNQ $\left(\mathrm{K}_{\mathrm{v}} 7\right)$ channels (Zhou et al., 2017), which in turn, results in increased AMPK activity.

\section{Calcium Activated $\mathrm{K}^{+}$Channels}

Calcium activated $\mathrm{K}^{+}$channels are a large family of $\mathrm{K}^{+}$selective channels with $6 / 7$ transmembrane domains that are abundant throughout the CNS (Faber and Sah, 2003). They are activated by rises in cytosolic calcium, which may occur when $\mathrm{Ca}_{\mathrm{v}}$ channels open during action potentials, leading to an influx of calcium. Three general $\mathrm{K}_{\mathrm{Ca}}$ subfamilies have been identified, which can be distinguished based on biophysical and pharmacological differences: large-conductance KCNMA1 (BK), intermediate-conductance KCNN4 (IK/SK4) and small

TABLE 3 | Potassium channels in the PVN.

\begin{tabular}{|c|c|c|c|c|c|}
\hline $\begin{array}{l}\text { Ion channel } \\
\text { family }\end{array}$ & General role & $\begin{array}{l}\text { Subtype } \\
\text { Identified }\end{array}$ & Method & Relevance & Reference \\
\hline \multirow[t]{4}{*}{$\begin{array}{l}K_{V} \\
\text { Voltage-activated }\end{array}$} & $\begin{array}{l}\text { Controlling action } \\
\text { potential } \\
\text { characteristics, } \\
\text { modulate neuronal } \\
\text { excitability }\end{array}$ & $\mathrm{K}_{\mathrm{V}} 1.1$ and $\mathrm{K}_{\mathrm{V}} 1.2$ & $\begin{array}{l}\text { Immunohistochemistry, } \\
\text { patch clamp } \\
\text { electrophysiology }\end{array}$ & $\begin{array}{l}\text { Downstream effectors of } \\
\text { NO on synaptic GABA } \\
\text { release }\end{array}$ & $\begin{array}{l}\text { Chung et al., 2001; } \\
\text { Yang et al., } 2007\end{array}$ \\
\hline & & $\mathrm{K}_{\mathrm{V} 1.4}$ and $\mathrm{K}_{\mathrm{v}} 4.3$ & Immunohistochemistry & "A"-type K+ current & $\begin{array}{l}\text { Sonner and Stern, } \\
\text { 2005; Sonner and } \\
\text { Stern, 2007; } \\
\text { Sonner et al., } 2008\end{array}$ \\
\hline & & $\begin{array}{l}\mathrm{K}_{\mathrm{v}} 1.2, \mathrm{~K}_{\mathrm{v}} 1.3 \\
\mathrm{~K}_{\mathrm{v}} 1.4, \mathrm{~K}_{\mathrm{v}} 4.1 \\
\mathrm{~K}_{\mathrm{v}} 4.2 \text { and } \mathrm{K}_{\mathrm{v}} 4.3\end{array}$ & $\begin{array}{l}\text { Patch clamp } \\
\text { electrophysiology } \\
\text { and RT-PCR }\end{array}$ & $\begin{array}{l}\uparrow \text { expression of } \mathrm{K}_{\mathrm{V}} 4.2 \text { and } \\
\mathrm{K}_{\mathrm{V}} 4.3 \text { in "type I" neurones }\end{array}$ & Lee et al., 2012 \\
\hline & & $\mathrm{K}_{\mathrm{V}} 7.2$ and $\mathrm{K}_{\mathrm{V}} 7.3$ & $\begin{array}{l}\text { Patch clamp } \\
\text { electrophysiology, } \\
\text { ICV in vivo } \\
\text { injections. }\end{array}$ & $\begin{array}{l}\text { Acute stress decreases } \\
\text { expression of } \mathrm{K}_{\mathrm{V}} 7.3 \text { and } \\
\text { blunts } \mathrm{M} \text {-current in } \mathrm{CRH} \\
\text { neurones. }\end{array}$ & Zhou et al., 2017 \\
\hline $\mathrm{K}_{\mathrm{Ca}}$ & $\begin{array}{l}\text { Regulate neuronal } \\
\text { excitability. }\end{array}$ & $\mathrm{BK}$ & Immunohistochemistry & Voltage-dependant & $\begin{array}{l}\text { Sausbier et al., } \\
2006\end{array}$ \\
\hline \multirow[t]{2}{*}{ Calcium-activated } & $\begin{array}{l}\text { Contribute to after- } \\
\text { hyperpolarization }\end{array}$ & & & & \\
\hline & & SK1, SK2, and SK3 & $\begin{array}{l}\text { Immunohistochemistry, } \\
\text { patch-clamp } \\
\text { electrophysiology, } \\
\text { targeted in vivo } \\
\text { injections }\end{array}$ & $\begin{array}{l}\text { Inhibition leads to } \uparrow \\
\text { excitability, } \uparrow \text { RSNA, } \uparrow S S N A \\
\uparrow H R, \uparrow B P \text { Decreased } \\
\text { functionality } \\
\uparrow \text { hyperexcitability }\end{array}$ & $\begin{array}{l}\text { Kohler et al., 1996; } \\
\text { Chen and Toney, } \\
\text { 2009; Gui et al., } \\
\text { 2012; Pachuau } \\
\text { et al., } 2014\end{array}$ \\
\hline $\mathrm{K}_{\text {ATP }}$ ATP-sensitive & $\begin{array}{l}\text { Modulate } \\
\text { excitability }\end{array}$ & - & $\begin{array}{l}\text { Patch-clamp } \\
\text { electrophysiology, } \\
\text { computational } \\
\text { modeling }\end{array}$ & $\begin{array}{l}\text { Adenosine } \downarrow \text { excitability via } \\
\text { adenosine receptors }\end{array}$ & $\begin{array}{l}\text { Lewis et al., 2010; } \\
\text { Li et al., } 2010\end{array}$ \\
\hline $\begin{array}{l}\text { GIRK g-protein } \\
\text { coupled inwardly } \\
\text { rectifying }\end{array}$ & $\begin{array}{l}\text { Synaptic inhibition } \\
\text { through activation } \\
\text { of GPCRs }\end{array}$ & $\begin{array}{l}\text { GIRK1, GIRK2, and } \\
\text { GIRK3 }\end{array}$ & $\begin{array}{l}\text { Immunohistochemistry, } \\
\text { in situ hybridization }\end{array}$ & $\begin{array}{l}\text { Role in presynaptic } \\
\text { inhibition of } \\
\text { neurotransmitter release? }\end{array}$ & $\begin{array}{l}\text { Morishige et al., } \\
\text { 1996; Shirasaka } \\
\text { et al., 2007; Saenz } \\
\text { del Burgo et al., } \\
2008\end{array}$ \\
\hline Kir & $\begin{array}{l}\text { Diverse functions } \\
\text { such as maintaining } \\
\text { action potential and } \\
\text { regulating insulin } \\
\text { release }\end{array}$ & Kir2.1 & & $\begin{array}{l}\text { Overexpression of Kir2.1 } \\
\text { controls excitability and } \\
\text { influences sympathetic } \\
\text { nervous system }\end{array}$ & $\begin{array}{l}\text { Geraldes et al., } \\
2014\end{array}$ \\
\hline K2P & $\begin{array}{l}\text { Similar to inward } \\
\text { rectifier, but } \mathrm{pH} \\
\text { sensitive }\end{array}$ & TASK-like & Patch-clamp & Conveys $\mathrm{pH}$ sensitivity & $\begin{array}{l}\text { Doroshenko and } \\
\text { Renaud, } 2009\end{array}$ \\
\hline
\end{tabular}


conductance KCNN1-3 channels (SK1, SK2 and SK3) (Sah, 1996; Vergara et al., 1998).

BK (encoded by KCNMA) and SK (encoded by one of four KCNN genes) channels are known to modulate firing in the brain (Kohler et al., 1996; Sausbier et al., 2006). Whilst one can confidently distinguish BK from SK channels pharmacologically, distinction of different KCNN subtypes is more difficult and so we use the generic term "SK" below. Patch-clamp electrophysiology recordings revealed the presence of an SK current in PVN-RVLM projecting neurones (Table 3). Inhibition of these channels with the SK channel blockers apamin and UCL1684, led to increased excitability of PVN-RVLM neurones in rats (Chen and Toney, 2009). In vivo investigations using targeted injections of pharmacological inhibitors of SK into the PVN induced increases in sympathetic nerve activity, heart rate and blood pressure (Gui et al., 2012). Although this work compliments the in vitro findings of Chen and Toney (2009), it is not possible to identify the neuronal population responsible for the responses observed. Recent evidence implicates a role for spinally projecting PVN neurones; patch-clamp recordings show that SK channel activity is reduced in hypertension (Pachuau et al., 2014), modulated by casein kinase II upregulation. This decreased functionality of SK contributes to the hyperactivity of these neurones (Pachuau et al., 2014). To add complexity to the role of SK, several investigations have suggested functional couplings to non-selective cation channels such as the transient receptor potential (TRP) channels (Gao and Wang, 2010; Earley, 2011). Work from our own group has verified the presence of SK channels in the PVN using immunohistochemistry and patch-clamp electrophysiology. We show that SK channels functionally couple to TRPV4 channels in the PVN (Feetham et al., 2015b). We discuss the mechanism above (including our mathematical model in Figures 3, 4), but further details include the fact that the $\mathrm{K}_{\mathrm{Ca}}$ channel involved in $\mathrm{PVN}$ osmosensing is SK and therefore sensitive to the antagonist UCL-1684.

Immunocytochemical staining of rat hypothalamic neurones has demonstrated BK $\beta 1$ (KCNMB1) expression in the PVN (Salzmann et al., 2010). In addition, a functional role for BK channels in the HPA-axis was investigated using genetically deficient mice for the pore forming KCNMA1 (BK) subunits (BK-/-). Reduced activation of hypothalamic PVN neurones was observed in response to stress in the BK-/- mouse, demonstrating an important role for KCNMA1 (BK) channels in HPA function in stress (Brunton et al., 2007).

\section{Inwardly Rectifying $\mathrm{K}^{+}$Channels}

Inwardly rectifying channels were first described in skeletal muscle, where a greater $\mathrm{K}^{+}$current into rather than out of the cell was observed; because this behavior is counter intuitive, it is sometimes referred to as the anomalous rectifier (Kubo et al., 1993). Broadly speaking there are strong and weak inward rectifier channels; the strong rectifiers including Kir2.x (KCNJ2), generally prevent any outward current flow (Dart et al., 1998), whereas the weaker inward rectifiers including Kir6.2 (KCNJ11) merely show inward rectification (Wellman et al., 1999).

These characteristics are very different from the voltage-gated $\mathrm{K}^{+}$currents discussed above (Nichols and Lopatin, 1997) as they have a tendency to electrically stabilize neurones near to the resting membrane potential, but inactivate once depolarization has been generated. Encoded by several KCNJ genes, they have diverse physiological functions such as regulating insulin release in pancreatic $\beta$-cells or modulation of heart rate myocytes (Nichols and Lopatin, 1997). There are seven subfamilies, but these are typically divided into 4 groups: Classical KCNJ2 channels (Kir2.x), G protein-gated KCNJ3 channels (Kir3.x), ATP-sensitive KCNJ11 channels (Kir6.x) and KCNJ transport channels (Kir1.x, Kir4.x, Kir5.x, and Kir7.x).

As previously mentioned, neurones in the PVN show an inwardly rectifying potassium current (Table 3 ). In studies by Geraldes et al. $(2014,2016)$ the inwardly rectifying potassium channel, Kir2.1 was overexpressed in spontaneously hypertensive rats using the lentivirus, leading to decreased blood pressure and decreased sympathetic output (Geraldes et al., 2014, 2016). G-protein coupled inwardly-rectifying potassium (GIRK) channels have also been shown to be widely distributed throughout the rodent brain. These channels are activated by several neurotransmitters and are important in synaptic inhibition (Brown, 1990; Hille, 1994), mediating the regulation of neuronal excitability via activation of G-protein coupled receptors. Three out of 4 GIRK subunits, GIRK1, GIRK2, and GIRK3 have all been shown to be present in the PVN using immunohistochemistry and in situ hybridization (Saenz del Burgo et al., 2008). GIRK1 specifically has been shown to be expressed presynaptically in the PVN, potentially having a role in presynaptic inhibition of neurotransmitter release (Morishige et al., 1996).

ATP-sensitive inwardly rectifying potassium $\left(\mathrm{K}_{\mathrm{ATP}}\right)$ channels were identified in spinally projecting neurones of the rat PVN by Li et al. (2010), where they mediate adenosine inhibition. $\mathrm{K}_{\text {ATP }}$ channels generally act as energy sensors (Nichols, 2006) and are closed by intracellular ATP. The first and most widely established role of $K_{\text {ATP }}$ channels [beyond the regulation of insulin secretion in pancreatic $\beta$-cells (Ashcroft and Rorsman, 1990)] is to suppress electrical activity as ATP levels fall, and this has been shown in cardiac, skeletal, and smooth muscle (Wellman et al., 1999). In neurones, their role is central to glucose sensing; as glucose levels increase, so does intracellular ATP and this closes $\mathrm{K}_{\mathrm{ATP}}$ channels and increases firing rate (Levin et al., 2004). Generally it is accepted that whilst hypothalamic neurones, including those in the PVN (Melnick et al., 2011), can be both excited or inhibited by glucose, only those excited by glucose are thought to involve $\mathrm{K}_{\mathrm{ATP}}$ channels. Since sympathetic activation by hypoglycaemia (Fagius, 2003) is poorly understood, but an important part of autonomic glucose counter regulation (Evans et al., 2003), we investigated whether PVN $\mathrm{K}_{\mathrm{ATP}}$ channels could also be involved with cellular inhibition of neuronal activity. Using a combination of mathematical modeling and patch-clamp electrophysiology (like that described above), we extended our sympathetic control neurone model to include $\mathrm{K}_{\mathrm{ATP}}$ as the only "glucose" sensor. In our model, KATP is expressed in both spinally projecting neurones and their GABAergic input neurones. We found that this model is sufficient to account for inhibition, no effect or activation, simply depending on the balance of $\mathrm{K}_{\mathrm{ATP}}$ channel conductance in the spinally 
projecting neurones themselves and the GABA-ergic inputs (Figure 5).

\section{Two-Pore Potassium Channels}

Two-pore domain potassium (K2P) channels are a structurally distinct subset of the mammalian $\mathrm{K}^{+}$channel superfamily widely distributed in the CNS, including the hypothalamus (Maingret et al., 2000; Hervieu et al., 2001; Medhurst et al., 2001; Han et al., 2003; Doroshenko and Renaud, 2009; Enyedi and Czirjak, 2010). The functional channel is a dimer with each subunit containing two pore-forming loops and four transmembrane domains (4TM/2P). In humans, $15 \mathrm{~K} 2 \mathrm{P}$ channel genes (KCNK) have been identified, which can be divided into six distinct subfamilies on the basis of both their structural/functional properties; TWIK, TASK, TREK, THIK, TALK, and TRESK. One of these channels has been specifically implicated in PVN function; it was shown that PVN neurones have a background (leak) pH-sensitive TASK-like current with patch-clamp electrophysiology (Doroshenko and Renaud, 2009). This was manifested as a large shift in resting membrane potential in response to extracellular $\mathrm{pH}$ changes. This channel may be involved with appetite control, since the authors showed that orexin-induced currents from PVN neurones were mediated by suppressing its activity (Doroshenko and Renaud, 2009).

\section{SODIUM CHANNELS}

Sodium channels are generally classified according to the trigger that opens them, for example, a voltage-change (termed "Voltage-gated" or " $\mathrm{Na}_{\mathrm{V}}$ channel") or binding of ligand (termed ligand-gated sodium channels). Sodium channels are important for generating electrical signals in neurons. $\mathrm{Na}_{\mathrm{v}}$ channels are ubiquitous in the central nervous system ( $\mathrm{Yu}$ and Catterall, 2003); their primary function in neurones is to generate and propagate action potentials (Catterall et al., 2005a). Sodium channels are of importance to the history of physiology; the work of Hodgkin and Huxley on sodium channels was a major milestone in electrophysiology (Hodgkin and Huxley, 1952).

In the brain, sodium channel proteins are composed of a complex of a $260 \mathrm{kDa} \alpha$ subunit in association with one or more auxiliary $\beta$ subunits ( $\beta 1, \beta 2$, and/or $\beta 3$ ) of $33-36 \mathrm{kDa}$ (Catterall, 2000a). Nine $\alpha$ subunits $\left(\mathrm{Na}_{\mathrm{v}} 1.1-\mathrm{Na}_{\mathrm{v}} 1.9\right)$ have been functionally characterized, and a tenth related isoform may also function as a $\mathrm{Na}^{+}$channel. The $\beta$-subunits are thought to be involved with trafficking or modulation of the $\alpha$-subunit (Molinarolo et al., 2018), although exactly how is not entirely clear. The $\alpha$-subunits, termed $\mathrm{Na}_{\mathrm{v}} 1$, are encoded by a family of genes called SCNA, of which, several have been discovered in the human genome. In total, 9 subtypes of $\mathrm{Na}_{\mathrm{v}}$ have been identified in mammals $\left(\mathrm{Na}_{\mathrm{v}} 1.1-1.9\right)$, with four $\alpha$ subunits found in the central nervous system; types I, II, III, and IV. In the CNS and heart, $\mathrm{Na}^{+}$ channels contain a mixture of $\beta 1-\beta 4$ subunits whereas in skeletal muscle, $\mathrm{Na}^{+}$channels only contain the $\beta 1$ subunit (Black and Waxman, 2013).
Tetrodotoxin, the guanidinium-containing blocker extracted from the Puffer fish, has contributed the most to our understanding of $\mathrm{Na}^{+}$channels. $\mathrm{Na}_{\mathrm{v}}$ channels can be classified by their sensitivity to TTX; SCN1A $\left(\mathrm{Na}_{\mathrm{v}} 1.1\right)$, SCN2A $\left(\mathrm{Na}_{\mathrm{v}} 1.2\right)$, SCN3A $\left(\mathrm{Na}_{\mathrm{v}} 1.3\right)$, SCN4A $\left(\mathrm{Na}_{\mathrm{v}} 1.4\right)$, SCN6A $\left(\mathrm{Na}_{\mathrm{V}} 1.6\right)$, and SCN7A $\left(\mathrm{Na}_{\mathrm{v}} 1.7\right)$ are blocked by low nanomolar concentrations of TTX; therefore, these subtypes are classified as TTX-sensitive, whereas, SCN5A $\left(\mathrm{Na}_{\mathrm{v}} 1.5\right)$, SCN8A $\left(\mathrm{Na}_{\mathrm{v}} 1.8\right)$, and SCN2A $\left(\mathrm{Na}_{\mathrm{v}} 1.9\right)$ are inhibited by only high micromolar TTX concentrations and are considered TTX-resistant channels.

Most neurones express a high density of TTX-sensitive $\mathrm{Na}^{+}$channels, carrying a large rapidly activating and rapidly inactivating 'transient' sodium current when membrane voltage is depolarized above threshold (typically near -55 to $-50 \mathrm{mV}$ ). This current has rapid kinetics, reaching its peak in less than a millisecond and declining to baseline within a few milliseconds, mediating the upstroke of the neuronal action potential. However, in addition, there is also a small slowly inactivating or non-inactivating sodium current, constituting a steady-state persistent sodium current (INaP) (Stafstrom, 2007; Carter et al., 2012). So whilst there are several ion channel types that conduct sodium ions, this section will focus on the voltagegated sodium channels $\left(\mathrm{Na}_{\mathrm{v}}\right)$ and epithelial sodium channels $(\mathrm{ENaC})$ which have both been shown to be present in the PVN (Table 4).

\section{Voltage-Gated Sodium Channels}

Several studies have described the expression pattern of $\mathrm{Na}_{\mathrm{v}}$ in the rodent CNS; however, these studies have focussed on expression rather than function (Westenbroek et al., 1989; Black et al., 1994; Whitaker et al., 2001). Using mRNA expression profiling the $\mathrm{Na}_{\mathrm{V}}$ subunits I, II, III have been identified throughout the rat hypothalamus, including in the PVN. The spatial distribution patterns of mRNA for subunits I, II, and III were shown to be very different, with type I expression being weak, and types II and III much stronger (Furuyama et al., 1993; Black et al., 1994). In summary, a range of voltage-gated sodium channels are expressed in the PVN, but there is not enough information to assess what specific functions these different isoforms may confer.

\section{The Epithelial Sodium Channel (ENaC)}

The epithelial sodium channel (ENaC) consists of combinations of four subunits: $\alpha, \delta, \beta$, and $\gamma$. These subunits are encoded by four genes: SCNN1a, SCNN1B, SCNN1G, and SCNN1D (Garty and Palmer, 1997). ENaC is best known for its role in $\mathrm{Na}^{+}$reabsorption in the nephron, but the presence of $\mathrm{ENaC}$ in the PVN has been identified using in situ hybridization. Weak immunoreactivity for $\mathrm{ENaC}$ has been shown in the parvocellular region of the PVN and not in the magnocellular region (Wang et al., 2010; Teruyama et al., 2012). Teruyama et al. (2012) have shown that there is immunoreactivity for the $\alpha-\mathrm{ENaC}$ subunit in both the parvocellular and magnocellular areas of the PVN. This immunoreactivity is co-localized with vasopressin and oxytocin only in the magnocellular cells of the PVN, suggesting 
A

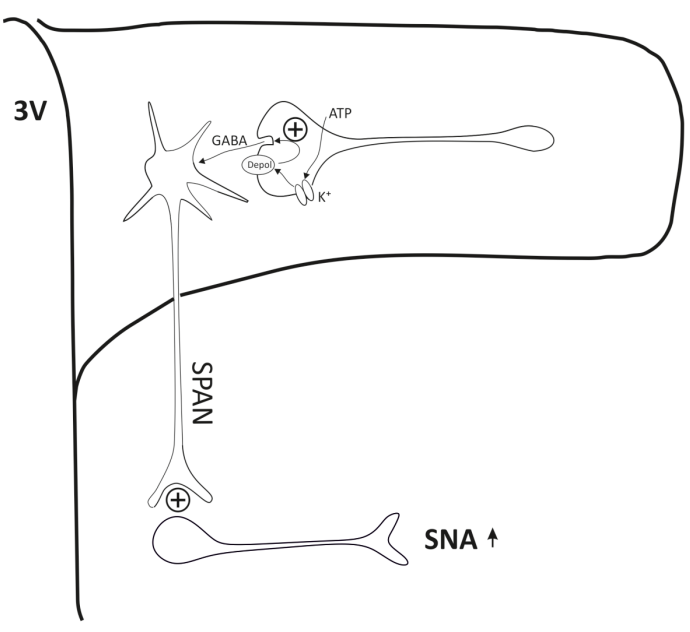

B

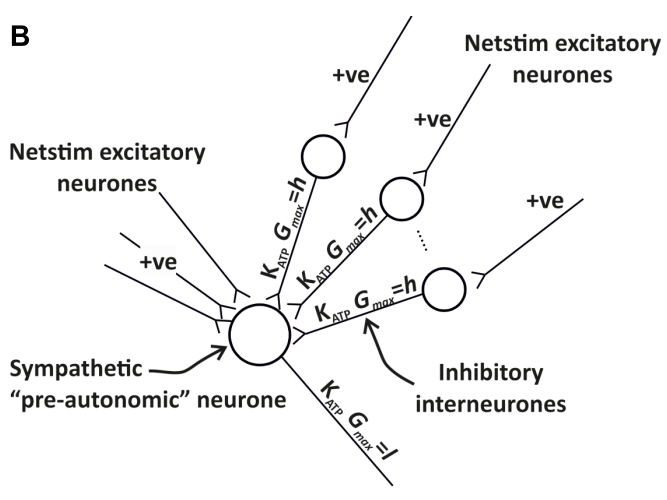

C

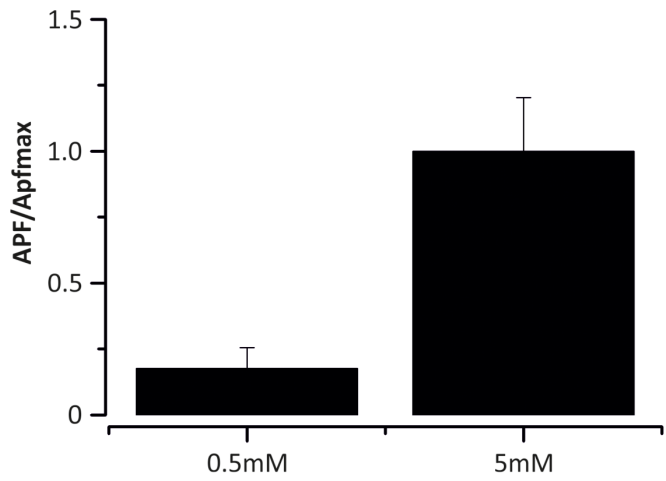

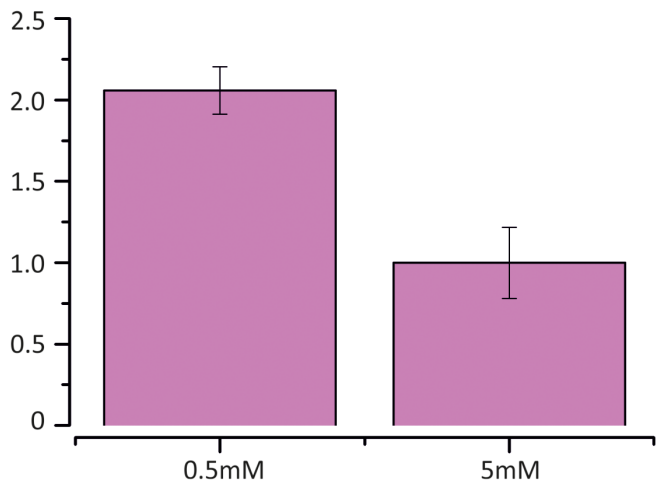

D

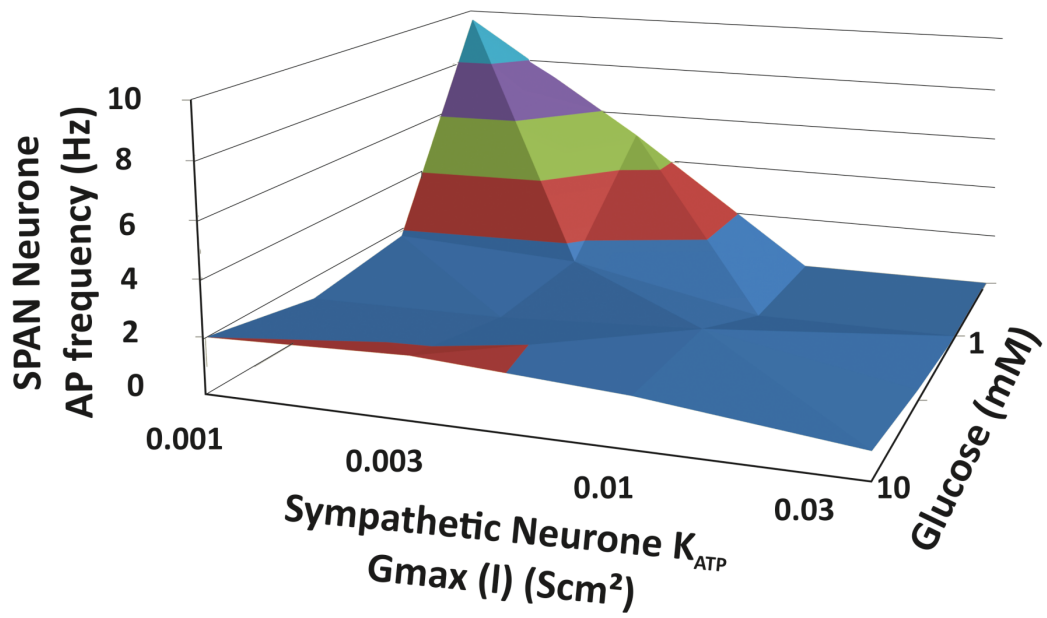

FIGURE 5 | Model of pre-autonomic neurone regulation by $\mathrm{K}_{\text {ATP }}$ channels. (A) The base model, spinally-projecting neurones (SPAN) receive excitatory and inhibitory input in the PVN and activate spinal preganglionic neurones. Both the SPAN and inhibitory interneurons express $\mathrm{K}_{\text {ATP }}$ channels, but at different densities (Shiraishi, 1987). (B) Parameterizing the model with different $K_{\text {ATP }}$ conductances (maximum) leave the cell to respond differently to glucose levels. (C) On the left, with low SPAN K KTP expression, increasing glucose excites the SPAN, but when $\mathrm{K}_{\text {ATP }}$ expression is sufficiently high, elevated glucose will decrease action potential frequency (APf). This paradox is accounted for by the relatively greater effect of glucose on the inhibitory input neurone. (D) A 3D dose response curve for ATP ion channel expression density ( $\mathrm{x}$-axis) and glucose concentration (z-axis) against the sympathetic neurone action current frequency ( $\mathrm{y}$-axis) generated from several experiments such as those in (C). 
a role in fluid regulation/diuresis within these cells. This group also performed voltage-clamp electrophysiology on magnocellular PVN neurones and applied the ENaC blocker benzamil, which reversibly reduced a steady-state inward current and decreased cell membrane conductance. Additionally, benzamil caused membrane hyperpolarization in the majority of vasopressin synthesizing magnocellular neurones and in around $50 \%$ of the oxytocin synthesizing neurones. ENaC in magnocellular neurones of the PVN will therefore affect firing patterns, and this in turn will ultimately control the secretion of vasopressin and oxytocin and fluid retention (Teruyama et al., 2012). Circumstantial evidence also suggests that PVN ENaC may contribute to hypertension. ENaC activity modulates sympathetic output and modulates blood pressure, an effect modulated by angiotensin receptors (Busst, 2013) known to be expressed in the PVN (specifically in spinally projecting autonomic neurones) (Oldfield et al., 2001). Furthermore, the salt-sensitive hypertension model (Liddle Syndrome) centers on the ENaC dependent elevation of cerebrospinal fluid sodium levels (Van Huysse et al., 2012).

\section{VOLTAGE-GATED CALCIUM CHANNELS}

Encoded by the CACNA gene, calcium channels show high selective permeability to calcium ions. Often referred to as voltage-dependent calcium channels (VDCCs), as distinct from ligand-gated calcium channels. VDCCs are activated by depolarized membrane potentials and allow the flow of $\mathrm{Ca}^{2+}$ into the cell, which, depending on the cell type can result in a range of physiological processes such as excitation, gene expression or release of hormones/neurotransmitters. VDCCs are formed as a complex of different subunits: $\alpha_{1}, \alpha_{2} \delta, \beta_{1-4}$, and $\gamma$. The $\mathrm{Ca}^{2+}$ selective pore is formed from the $\alpha_{1}$ subunit which contains the voltage-sensing domain and drug binding sites (Catterall, 2000b) and associated subunits have several functions including modulation of channel gating. VDCCs can be divided into three categories depending on the subunits expressed: (1) High-voltage activated dihydropyridine-sensitive L-type CACNA1 ( $\left.\mathrm{Ca}_{\mathrm{v}} 1 . \mathrm{x}\right)$ channels, (2) High-voltage activated dihydropyridine-insensitive CACNA1 $\left(\mathrm{Ca}_{\mathrm{v}} 2 . \mathrm{x}\right)$ channels and (3) Low-voltage activated T-type CACNA1 $\left(\mathrm{Ca}_{\mathrm{v}} 3 . \mathrm{x}\right)$ channels, all expressing a variety of subunits (Catterall et al., 2005b).

TABLE 4 | Other channels in the PVN.

\begin{tabular}{lllll}
\hline $\begin{array}{l}\text { Ion channel } \\
\text { family }\end{array}$ & General role & $\begin{array}{l}\text { Subtype } \\
\text { Identified }\end{array}$ & Method & Relevance \\
\hline
\end{tabular}

\section{Sodium channels}

$\mathrm{Nav}$

Voltage-activated

ENaC Epithelial

sodium channel

Calcium channels

Cav

Voltage-activated

\section{Others}

P2X-purinoreceptors ATP-gated

\section{ASICs}

Acid-sensing

$\mathrm{HCN}$

Hyperpolarization-

activated,

cyclic-nucleotide-

gated
Generate and propagate action potentials

Sodium

homeostasis

Involved in muscle contraction and excitation of neurones

T-type (Cav3.x) (Cav3.1)

Mediate fast

synaptic

transmission

$\mathrm{pH}$ sensing

Modulating

pacemaker activity type III

L-type (Cav1.x)

P2X1-6

HCN1-4
Type I, type II, and

Immunohistochemistry, RT-PCR

In situ hybridization

Immunohistochemistry

Patch clamp electrophysiology, RT-PCR, immunohistochemistry

Immunohistochemistry

RT-PCR, Western

blot

RT-PCR
Expression profiles:

Type I weak

Type II and III strong

Weak immunoreactivity

Westenbroek et al., 1989;

Furuyama et al., 1993;

Black et al., 1994; Whitaker et al., 2001; Jarnot and

Corbett, 2006

Wang et al., 2010;

Teruyama et al., 2012

Chin et al., 1992;

Hetzenauer et al., 2006

Tasker and Dudek, 1991; Perez-Reyes, 1999, 2003; Luther and Tasker, 2000; Stern, 2001; Luther et al., 2002; Sonner and Stern, 2007; Lee et al., 2008

\section{Cham et al., 2006}

These receptor channels are often linked to inflammation, but this has not been studied in the PVN (in relation to P2X)

Hyperpolarization activated current responsible for pacemaker activity
Meng et al., 2009

Monteggia et al., 2000; Shirasaka et al., 2007 
L-type CACNA1 $\left(\mathrm{Ca}_{\mathrm{v}}\right)$ channels have been identified in both magnocellular and parvocellular regions of the rat PVN using in situ hybridization and immunohistochemistry (Chin et al., 1992) (Table 4). Hetzenauer et al. (2006) investigated the presence of the dihydropyridine-sensitive L-type calcium channels CACNA1C $\left(\mathrm{Ca}_{\mathrm{v}} 1.2\right)$ and CACNA1D $\left(\mathrm{Ca}_{\mathrm{v}} 1.3\right)$ throughout the mouse brain (Hetzenauer et al., 2006). By using the dihydropyridine-sensitive L-type calcium channel activator BayK 8644 in the mutant $\mathrm{Ca}_{\mathrm{V}} 1.2^{\mathrm{DHP}-/-}$ mouse, it was possible to determine whether the increase in neuronal activity (using $c$-fos as an indicator) was due to CACNA1C $\left(\mathrm{Ca}_{\mathrm{v}} 1.2\right)$ or CACNA1D $\left(\mathrm{Ca}_{\mathrm{V}} 1.3\right)$. Within the PVN, $c$-fos in BayK treated mutant mice was markedly increased compared to other areas of the brain, suggesting this area is predominantly CACNA1D $\left(\mathrm{Ca}_{\mathrm{v}} 1.3\right)$ L-type calcium-mediated activation, rather than CACNA1C $\left(\mathrm{Ca}_{\mathrm{v}} 1.2\right)$ (Hetzenauer et al., 2006). Although L-type VDCCs are present throughout the PVN, the predominant VDCC current identified in parvocellular cells to date is the (transient) T-type $\mathrm{Ca}^{2+}$ current (as opposed to voltage-gated $\mathrm{K}^{+}$channels in magnocellular cells of the PVN as discussed earlier) (Tasker and Dudek, 1991; Luther and Tasker, 2000). T-type $\mathrm{Ca}^{2+}$ channels modulate neuronal function via regulation of $\mathrm{Ca}^{2+}$ influx into the neurone, leading to cell depolarization and action potential firing. Specifically, these channels are important in generating and regulating action potentials, influencing pacemaker activity and action potential bursting behavior (Perez-Reyes, 1999, 2003). Patch-clamp recordings made from retrogradely labeled neurosecretory and non-labeled non-secretory parvocellular cells of rat PVN, showed that non-secretory parvocellular cells generate a low-threshold spike via T-type $\mathrm{Ca}^{2+}$ channels, whereas this is not seen in identified neurosecretory neurones (Stern, 2001; Luther et al., 2002; Sonner and Stern, 2007). This study further confirmed the idea that different groups of cells in the parvocellular area of the PVN exhibit different membrane properties. Additionally, more recent studies involving a combination of RT-PCR, immunohistochemistry and patchclamp recordings have indicated that CACNA1G $\left(\mathrm{Ca}_{\mathrm{v}} 3.1\right)$ is the major subtype of channel expressed in pre-autonomic cells mediating the T-type $\mathrm{Ca}^{2+}$ dependent low threshold spikes (Lee et al., 2008). These results provide clear evidence that modulation of these channels is vital for normal activity of pre-autonomic PVN neurones.

\section{OTHER ION CHANNELS}

Above we have discussed the major families of ion channels identified in the PVN and finally we cover ion channels where there are only isolated studies of expression in the PVN (Table 4). For example, the P2 purinergic membrane receptor family comprises several subtypes that are commonly activated by extracellular nucleotides (ATP or ADP). P2X receptor channels are ligand-gated ion channel receptors (P2X1-7), whereas P2Y are G-protein coupled receptors. Double-labeling fluorescence immunohistochemistry shows that, in the PVN, vasopressincontaining neurones largely also expressed P2X4, P2X5, and $\mathrm{P} 2 \mathrm{X} 6$ receptors, while oxytocin-containing neurones expressed
P2X4 receptors. Since purinergic pharmacology is relatively advanced compared to many of the other channels discussed above, these constitute ideal future candidates for experimental analysis of PVN regulation of autonomic control (Guo et al., 2009).

Acid-sensing ion channels (ASICs) are proton-gated voltageinsensitive cation channels, responsible, as their names suggests, for sensing $\mathrm{pH}$. In mammals, ASIC are encoded by five genes that produce ASIC protein subunits: ASIC1, ASIC2, ASIC3, ASIC4, and ASIC5. Immunoreactivity has been shown to be high in the rat PVN for ASIC3 (Meng et al., 2009) and ASIC4 mRNA has been identified within the PVN using radioactive in situ hybridization (Hoshikawa et al., 2017), suggesting an acid sensing role for neurones within this area. However, no functional studies have been performed.

Pacemaker activity of some PVN hypothalamic neurones is modulated by a hyperpolarization activated current (Ih) (Shirasaka et al., 2007). A family of channels, hyperpolarizationactivated, cyclic nucleotide-gated (HCN) channels, has been identified as responsible for this pacemaker activity in neuronal cells. A study by Monteggia et al. (2000) identified four members of this family $\mathrm{HCN} 1-4$ with verifying expression patterns throughout the rat brain. All members of this family were shown to be present within the PVN; with expression profiles for mRNA ranging from weak for $\mathrm{HCN} 2$ to extremely strong for HCN3 (Monteggia et al., 2000).

Surprisingly, although dogma states that anion channels, such as chloride channels, would be present in the plasma membrane of all cells, no studies have been reported on their presence in the PVN. Chloride channels are functionally and structurally diverse with a range of functions such as cell volume regulation, regulation of $\mathrm{pH}$ and cell membrane potential control. As one of the main functions of these channels is to regulate excitability of neurones it is likely that chloride channels would be present within the PVN (Hille, 1986).

A vast variety of ion channels exist in mammalian biology, each with diverse physiological functions. It is likely that each channel subtype will contribute to the resting membrane potential of PVN neurones with the ability to modulate firing activity and the more we know about these the better our predictive neuronal models will be and the closer we will be to selectively modulating particular neurones without adversely effecting others. There will be many additional PVN channels that are not discussed here, some of these have been include in the tables, and others are, naturally, yet to be discovered.

\section{PVN ION CHANNELS IN DISEASE}

The PVN is linked to several important physiological processes and one of the exciting prospects for the future is to uncover whether changes in PVN ion channel expression or activity might contribute to pathological changes and could be pharmacologically (or biologically) interdicted. This is because there are several ion channel modulating drugs on the market and many new ones in production (Humphries and Dart, 2015). To date, there are a few lines of direct evidence that PVN ion channel 
changes underlie diseases; such evidence principally focusses around four conditions; diabetes, hypertension, heart failure and hormonal changes associated with depression.

\section{Diabetes}

In a mouse model of spontaneous type 2 diabetes $(\mathrm{db} / \mathrm{db})$, it was shown that identified liver-related PVN neurones were significantly more active (the majority fired spontaneously) compared to those of control (lean) mice (where the majority of neurones were silent) (Gao et al., 2017). This could be explained by an increase in TRPC channels, since mRNA for TRPC1,4,6 and 6 were all show, by qPCR to increase in the streptozotocin T2D model (Zheng et al., 2014).

\section{Hypertension}

Two separate lines of evidence implicate ion channel changes in hypertension. We described above that the small $\mathrm{Ca}^{2+}$ sensitive potassium channel (SK) expression was decreased in spinally projecting (sympathetic) neurones in hypertension (Pachuau et al., 2014). This could either be contributory to hypertension or resultant from hypertension, but since decrease in expression would be expected to increase neuronal activity the former seems more likely. Over expression of glutamate receptors also contributes to sympathetic hyperexcitability in spontaneously hypertensive rats ( $\mathrm{Li}$ et al., 2014), although this type of receptor plasticity could be secondary to elevated angiotensin levels, since Glass et al. (2015) showed that NMDA levels increase in neuronal nitric oxide synthase (nNOS)-expressing PVN neurones following just 2 weeks of angiotensin treatment leaving animals with elevated blood pressure. Together these data suggest that PVN NMDA receptor plasticity may well contribute to development of hypertension.

\section{Heart Failure}

The PVN has been linked to cardiovascular diseases such as hypertension and heart failure, where an elevation in sympathetic nerve activity is observed (Zhang et al., 2002; Guyenet, 2006). For example, dysfunction of the tonic regulation of the PVN has been suggested to play a role in progression of heart failure (Pyner, 2014). In addition, lesioning of the PVN prevents the development of spontaneous hypertension in SHRs (Takeda et al., 1991). Interestingly, PCR data showed that mRNA expression levels of $\alpha 1$ subunit and $\beta 1$ receptors were significantly lower in a rat model of chronic heart failure, suggesting that tonic inhibition (mediated by GABA receptors in the PVN) of sympathetic output may be blunted in chronic heart failure (Wang et al., 2009).

Over expression of kainate receptor-channels also contributes to sympathetic hyperexcitability in spontaneously hypertensive rats (Li et al., 2014). Additionally, inhibited GABA-ergic neurotransmission contributes to this phenomenon in models of heart failure (Patel, 1997; Pyner, 2014). Briefly, sympathetic output is elevated in the chronic heart failure model, at the level of the PVN (Zhang et al., 2002; Li and Patel, 2003), following changes in reactive oxygen/nitric oxide pathways together with increases in pro-inflammatory cytokines and prostaglandins (Zubcevic et al., 2011). Plasma cytokines are elevated in male mild hypertensives (Chae et al., 2001) and this changed neuroinflammatory status of cardiovascular control nuclei appears to be of central, rather than systemic origin (Waki et al., 2008). It is not clear whether this is causal or resultant from hypertension, but it seems an important phenomenon. Rats with induced heart failure have reduced nNOS (Zhang et al., $1997,2002)$. Additionally, cytokines in the PVN up-regulate AT$1 \mathrm{R}$ expression and deplete nNOS (Guggilam et al., 2008). Since nNOS produces NO that facilitates tonic inhibition of PVN GABA neurotransmission, this dis-inhibition scheme serves to exaggerate sympathetic output in heart failure rats. Ultimately, block of cytokines (TNF in particular) appears to limit the overall PVN sympathoexcitation (Guggilam et al., 2007, 2008, 2011).

\section{Other Diseases}

Hypertension and heart failure are not the only diseases mediated by GABA neurotransmission, and since the PVN is at the core of autonomic-endocrine integration, it is no surprise that it is involved in a variety of diseases/disorders. For example, HPA stress responses are initiated by CRH neurones within the PVN and the HPA axis are known to be activated in depressive disorders (Varghese and Brown, 2001). Remarkably, the total number of $\mathrm{CRH}$-immunoreactive neurones is four times higher in depressed patients compared to healthy individuals (Raadsheer et al., 1993) despite an overall reduction in total PVN neurone numbers (50\%) in major depression and bipolar patients (Manaye et al., 2005). In a recent study, Gao et al. (2013) looked at both isoforms of glutamic acid decarboxylase $\left(\mathrm{GAD}_{65 / 67}\right)$ (the synthetic enzyme for GABA) as a marker to monitor GABAergic neurotransmission in the PVN. They reported a reduction in the density of $\mathrm{GAD}_{65 / 67}$ in the PVN of major depressive disorder patients (Gao et al., 2013). They also reported a negative correlation between the density of $\mathrm{GAD}_{65 / 67}$-immunoreactive (ir) and the number of CRH-ir neurones in the PVN in the depression group, but not in the control group. Interestingly, no change in neuronal numbers was observed in other areas of the hypothalamus such as the supraoptic nucleus (Gao et al., 2013).

\section{LIMITATIONS}

In this review, we provide a summary of our knowledge of PVN ion channel expression and function to date. In the above passages we address all ion channel studies we are aware of that was conducted in the PVN. It should be noted that each type of study has its strengths and weaknesses, but we take each authors peer reviewed data at face value, neutrally and without judgment. For example, the physiological and electrophysiological approach we adopt ourselves is heavily dependent upon ion channel pharmacology, it has the strength that you can see what the channel does or determine its electrical fingerprint, but the agonists and antagonists are rarely as selective as one would wish. There are molecular approaches available, siRNA for example, but these are very difficult to deploy in native tissue. Whilst it would be considered controversial for some, even ordinary knock-down studies have the profound limitation that we know considerable compensatory expression will take place and muddy conclusions drawn. qPCR, microarray or even RNA sequencing 
are powerful approaches, but unless backed-up with some other type of study, show only the transcript expression not the ion channel protein itself. Even if backed up by Western blot analysis, these studies do not reveal whether there is patent membrane expression or whether ion channel function is compromised or altered. Immunohistochemistry can often suffer from issues of non-selective binding etc., unless properly validated, but again it does not tell us about the functional integrity of the channel. It is also very difficult to definitively link, directly, any of the protein or mRNA data directly to the patch-clamp data presented, or visa-versa.

\section{CONCLUSION}

In this review we have brought together information on the expression and role of a wide range of ion channels in the PVN. Since the PVN is central to autonomic and endocrine regulation of homeostasis these channels may in the future emerge as therapeutic targets. Our own research focuses on cardiovascular control, but there is clear potential for intervention in a wide range of areas. Several challenges remain; least of all not access to this area of the forebrain. Clearly the future will lead not just information on which ion channels are present and potential targets for intervention, but mechanisms to get that drug or biologic to the target area. In the work of Geraldes et al. (2014), this was achieved by intracranial microinjection and our own unpublished work shows we can deliver biologics to the PVN via spinal injection, but these are still not attractive avenues for medical deployment of treatments. Of course, most centrally acting drugs; sedatives, anesthetics and supraspinal analgesics are effective without any such targeting. This may too prove useful for therapeutic targeting of PVN ion channels. The diversity of ion channels, receptors and neurotransmitters within the PVN

\section{REFERENCES}

Alexander, S. P., Kelly, E., Marrion, N., Peters, J. A., Benson, H. E., Faccenda, E., et al. (2015). The concise guide to PHARMACOLOGY 2015/16: overview. Br. J. Pharmacol. 172, 5729-5743. doi: 10.1111/bph.13347

Amir, S. (1990). Stimulation of the paraventricular nucleus with glutamate activates interscapular brown adipose-tissue thermogenesis in rats. Brain Res. 508, 152-155. doi: 10.1016/0006-8993(90)91129-5

Ashcroft, F. M., and Rorsman, P. (1990). Atp-sensitive K+ channels - a link between B-Cell metabolism and insulin-secretion. Biochem. Soc. Trans. 18, 109-111. doi: 10.1042/bst0180109

Badoer, E. (2001). Hypothalamic paraventricular nucleus and cardiovascular regulation. Clin. Exp. Pharmacol. Physiol. 28, 95-99. doi: 10.1046/j.1440-1681. 2001.03413.x

Baertschi, A. J., Beny, J. L., and Makara, G. B. (1983). Paraventricular nucleus region controls pituitary-adrenal function in Brattleboro rats. Am. J. Physiol. 244, R363-R367. doi: 10.1152/ajpregu.1983.244.3.R363

Barrett-Jolley, R. (2001). Nipecotic acid directly activates GABA(A)-like ion channels. Br. J. Pharmacol. 133, 673-678. doi: 10.1038/sj.bjp.070 4128

Barrett-Jolley, R., Pyner, S., and Coote, J. H. (2000). Measurement of voltage-gated potassium currents in identified spinally-projecting sympathetic neurones of the paraventricular nucleus. J. Neurosci. Methods 102, 25-33. doi: 10.1016/ S0165-0270(00)00271-5

Biag, J., Huang, Y., Gou, L., Hintiryan, H., Askarinam, A., Hahn, J. D., et al. (2012). Cyto- and chemoarchitecture of the hypothalamic paraventricular nucleus in
(Pyner, 2009; Nunn et al., 2011) is such that there may be targets that can be preferentially and beneficially activated with systemic application, as for other neuropharmacological agents, albeit they have largely been discovered by serendipity rather than design. Another challenge will be continuing the identification of biophysical and pharmacological profiles of specific subtypes of PVN neurone. Whilst the PVN is a relatively small nucleus comprising about $1 \%$ of the brain, data from different studies are not easily separated into different categories of neurone. Our work has modeled the biophysical properties of spinally projecting or parvocellular neurones, but these will likely consist of mixed populations. The earliest studies identified the so called type I and II neurones and this advanced recently with the single cell PCR work of Lee et al. (2012). Since it is believed that type II neurones largely constitute pre-autonomic neurones, this allows for refinement of predictive models of neuronal behavior. However, we are far off understanding the PVN as a network, with differential outputs to cardiovascular and other targets and inputs from the several sources the PVN receives. The rapid accumulation of ion channel data over the past 20 years does, however, already give considerable optimism for rationally designed therapeutic interventions in the future.

\section{AUTHOR CONTRIBUTIONS}

All authors listed have made a substantial, direct and intellectual contribution to the work, and approved it for publication.

\section{FUNDING}

BBSRC Grant no. BB/N003020/1.

the C57BL/6J male mouse: a study of immunostaining and multiple fluorescent tract tracing. J. Comp. Neurol. 520, 6-33. doi: 10.1002/cne.22698

Black, J. A., and Waxman, S. G. (2013). Noncanonical roles of voltage-gated sodium channels. Neuron 80, 280-291. doi: 10.1016/j.neuron.2013.09.012

Black, J. A., Yokoyama, S., Higashida, H., Ransom, B. R., and Waxman, S. G. (1994). Sodium channel mRNAs I, II and III in the CNS: cell-specific expression. Brain Res. Mol. Brain Res. 22, 275-289. doi: 10.1016/0169-328X(94) 90056-6

Bourque, C. W. (2008). Central mechanisms of osmosensation and systemic osmoregulation. Nat. Rev. Neurosci. 9, 519-531. doi: 10.1038/nrn2400

Bourque, C. W., and Oliet, S. H. (1997). Osmoreceptors in the central nervous system. Annu. Rev. Physiol. 59, 601-619. doi: 10.1146/annurev.physiol.59.1.601

Broberger, C., Visser, T. J., Kuhar, M. J., and Hokfelt, T. (1999). Neuropeptide $\mathrm{Y}$ innervation and neuropeptide-Y-Y1-receptor-expressing neurons in the paraventricular hypothalamic nucleus of the mouse. Neuroendocrinology 70, 295-305. doi: 10.1159/000054490

Brown, D. A. (1990). G-proteins and potassium currents in neurons. Annu. Rev. Physiol. 52, 215-242. doi: 10.1146/annurev.ph.52.030190.001243

Brunton, P. J., Sausbier, M., Wietzorrek, G., Sausbier, U., Knaus, H. G., Russell, J. A., et al. (2007). Hypothalamic-pituitary-adrenal axis hyporesponsiveness to restraint stress in mice deficient for large-conductance calcium- and voltage-activated potassium (BK) channels. Endocrinology 148, 5496-5506. doi: 10.1210/en.2007-0319

Buijs, R. M., La Fleur, S. E., Wortel, J., Van Heyningen, C., Zuiddam, L., Mettenleiter, T. C., et al. (2003). The Suprachiasmatic nucleus balances sympathetic and parasympathetic output to peripheral organs through separate 
preautonomic neurons. J. Comp. Neurol. 464, 36-48. doi: 10.1002/cne. 10765

Busst, C. J. (2013). Blood pressure regulation via the epithelial sodium channel: from gene to kidney and beyond. Clin. Exp. Pharmacol. Physiol. 40, 495-503. doi: 10.1111/1440-1681.12124

Carreno, F. R., Ji, L. L., and Cunningham, J. T. (2009). Altered central TRPV4 expression and lipid raft association related to inappropriate vasopressin secretion in cirrhotic rats. Am. J. Physiol. Regul. Integr. Comp. Physiol. 296, R454-R466. doi: 10.1152/ajpregu.90460.2008

Carter, B. C., Giessel, A. J., Sabatini, B. L., and Bean, B. P. (2012). Transient sodium current at subthreshold voltages: activation by EPSP waveforms. Neuron 75 , 1081-1093. doi: 10.1016/j.neuron.2012.08.033

Castel, M., and Morris, J. F. (1988). The neurophysin-containing innervation of the forebrain of the mouse. Neuroscience 24, 937-966. doi: 10.1016/0306-4522(88) 90078-4

Caterina, M. J. (2007). Transient receptor potential ion channels as participants in thermosensation and thermoregulation. Am. J. Physiol. Regul. Integr. Comp. Physiol. 292, R64-R76. doi: 10.1152/ajpregu.00446.2006

Catterall, W. A. (2000a). From ionic currents to molecular mechanisms: the structure and function of voltage-gated sodium channels. Neuron 26, 13-25. doi: 10.1016/S0896-6273(00)81133-2

Catterall, W. A. (2000b). Structure and regulation of voltage-gated Ca2+ channels. Annu. Rev. Cell Dev. Biol. 16, 521-555.

Catterall, W. A., Goldin, A. L., and Waxman, S. G. (2005a). International union of pharmacology. XLVII. Nomenclature and structure-function relationships of voltage-gated sodium channels. Pharmacol. Rev. 57, 397-409.

Catterall, W. A., Perez-Reyes, E., Snutch, T. P., and Striessnig, J. (2005b). International union of pharmacology. XLVIII. Nomenclature and structurefunction relationships of voltage-gated calcium channels. Pharmacol. Rev. 57, 411-425.

Chae, C. U., Lee, R. T., Rifai, N., and Ridker, P. M. (2001). Blood pressure and inflammation in apparently healthy men. Hypertension 38, 399-403. doi: 10.1161/01.HYP.38.3.399

Cham, J. L., and Badoer, E. (2008). Hypothalamic paraventricular nucleus is critical for renal vasoconstriction elicited by elevations in body temperature. Am. J. Physiol. Ren. Physiol. 294, F309-F315. doi: 10.1152/ajprenal.00488.2007

Cham, J. L., Klein, R., Owens, N. C., Mathai, M., McKinley, M., and Badoer, E. (2006). Activation of spinally projecting and nitrergic neurons in the PVN following heat exposure. Am. J. Physiol. Regul. Integr. Comp. Physiol. 291, R91-R101. doi: 10.1152/ajpregu.00675.2005

Chen, F., Dworak, M., Wang, Y., Cham, J. L., and Badoer, E. (2008). Role of the hypothalamic PVN in the reflex reduction in mesenteric blood flow elicited by hyperthermia. Am. J. Physiol. Regul. Integr. Comp. Physiol. 295, R1874-R1881. doi: 10.1152/ajpregu.90384.2008

Chen, J., Gomez-Sanchez, C. E., Penman, A., May, P. J., and Gomez-Sanchez, E. (2014). Expression of mineralocorticoid and glucocorticoid receptors in preautonomic neurons of the rat paraventricular nucleus. Am. J. Physiol. Regul. Integr. Comp. Physiol. 306, R328-R340. doi: 10.1152/ajpregu.00506. 2013

Chen, Q., and Pan, H.-L. (2006). Regulation of synaptic input to hypothalamic presympathetic neurons by $\mathrm{GABA}_{\mathrm{B}}$ receptors. Neuroscience 142, 595-606. doi: 10.1016/j.neuroscience.2006.06.039

Chen, Q. H., and Toney, G. M. (2001). AT(1)-receptor blockade in the hypothalamic PVN reduces central hyperosmolality-induced renal sympathoexcitation. Am. J. Physiol. Regul. Integr. Comp. Physiol. 281, R1844-R1853. doi: 10.1152/ajpregu.2001.281.6.R1844

Chen, Q. H., and Toney, G. M. (2009). Excitability of paraventricular nucleus neurones that project to the rostral ventrolateral medulla is regulated by small-conductance Ca2+-activated K+ channels. J. Physiol. 587, 4235-4247. doi: 10.1113/jphysiol.2009.175364

Chin, H., Smith, M. A., Kim, H. L., and Kim, H. (1992). Expression of dihydropyridine-sensitive brain calcium channels in the rat central nervous system. FEBS Lett. 299, 69-74. doi: 10.1016/0014-5793(92)80103-N

Chu, C.-P., Kannan, H., and Qiu, D.-L. (2010). Effect of hypertonic saline on rat hypothalamic paraventricular nucleus parvocellular neurons in vitro. Neurosci. Lett. 482, 142-145. doi: 10.1016/j.neulet.2010.07.019

Chung, Y. H., Kim, H. S., Shin, C. M., Kim, M. J., and Cha, C. I. (2001). Immunohistochemical study on the distribution of voltage-gated $\mathrm{K}(+)$ channels in rat brain following transient focal ischemia. Neurosci. Lett. 308, 157-160. doi: 10.1016/S0304-3940(01)01996-6

Clapham, D. E. (2003). TRP channels as cellular sensors. Nature 426, 517-524. doi: 10.1038/nature02196

Coetzee, W. A., Amarillo, Y., Chiu, J., Chow, A., Lau, D., McCormack, T., et al. (1999). Molecular diversity of K+ channels. Ann. N. Y. Acad. Sci. 868, 233-285. doi: 10.1111/j.1749-6632.1999.tb11293.x

Coote, J. H. (2007). Landmarks in understanding the central nervous control of the cardiovascular system. Exp. Physiol. 92, 3-18. doi: 10.1113/expphysiol.2006. 035378

Cui, L. N., Coderre, E., and Renaud, L. P. (2001). Glutamate and GABA mediate suprachiasmatic nucleus inputs to spinal- projecting paraventricular neurons. Am. J. Physiol. Regul. Integr. Comp. Physiol. 281, R1283-R1289. doi: 10.1152/ ajpregu.2001.281.4.R1283

Cullinan, W. E. (2000). GABA(A) receptor subunit expression within hypophysiotropic CRH neurons: a dual hybridization histochemical study. J. Comp. Neurol. 419, 344-351. doi: 10.1002/(SICI)1096-9861(20000410)419: 3<344::AID-CNE6>3.0.CO;2-Z

Dampney, R. A. (1994). Functional organization of central pathways regulating the cardiovascular system. Physiol. Rev. 74, 323-364. doi: 10.1152/physrev.1994.74. 2.323

Dart, C., Leyland, M. L., Barrett-Jolley, R., Shelton, P. A., Spencer, P. J., Conley, E. C., et al. (1998). The dependence of Ag+ block of a potassium channel, murine Kir2.1, on a cysteine residue in the selectivity filter. J. Physiol. 511, 15-24. doi: 10.1111/j.1469-7793.1998.015bi.x

Deering, J., and Coote, J. H. (2000). Paraventricular neurones elicit a volume expansion-like change of activity in sympathetic nerves to the heart and kidney in the rabbit. Exp. Physiol. 85, 177-186. doi: 10.1111/j.1469-445X.2000.01953.x

DiMicco, J. A., Samuels, B. C., Zaretskaia, M. V., and Zaretsky, D. V. (2002). The dorsomedial hypothalamus and the response to stress: part renaissance, part revolution. Pharmacol. Biochem. Behav. 71, 469-480. doi: 10.1016/S00913057(01)00689-X

DiMicco, J. A., StotzPotter, E. H., Monroe, A. J., and Morin, S. M. (1995). Role of the dorsomedial hypothalamus in the cardiovascular response to stress. Clin. Exp. Pharmacol. Physiol. 23, 171-176. doi: 10.1111/j.1440-1681.1996.tb02592.x

Doroshenko, P., and Renaud, L. P. (2009). Acid-sensitive TASK-like K+ conductances contribute to resting membrane potential and to orexininduced membrane depolarization in rat thalamic paraventricular nucleus neurons. Neuroscience 158, 1560-1570. doi: 10.1016/j.neuroscience.2008. 12.008

Duan, Y. F., Winters, R., McCabe, P. M., Green, E. J., Huang, Y., and Schneiderman, N. (1997). Cardiorespiratory components of defense reaction elicited from paraventricular nucleus. Physiol. Behav. 61, 325-330. doi: 10.1016/ S0031-9384(96)00410-6

Earley, S. (2011). Endothelium-dependent cerebral artery dilation mediated by transient receptor potential and $\mathrm{Ca} 2+$-activated $\mathrm{K}+$ channels. J. Cardiovasc. Pharmacol. 57, 148-153. doi: 10.1097/FJC.0b013e3181f580d9

Enyedi, P., and Czirjak, G. (2010). Molecular background of leak K+ currents: two-pore domain potassium channels. Physiol. Rev. 90, 559-605. doi: 10.1152/ physrev.00029.2009

Evans, S. B., Wilkinson, C. W., Gronbeck, P., Bennett, J. L., Taborsky, G. J., and Figlewicz, D. P. (2003). Inactivation of the PVN during hypoglycemia partially simulates hypoglycemia-associated autonomic failure. Am. J. Physiol. Regul. Integr. Comp. Physiol. 284, R57-R65. doi: 10.1152/ajpregu.00439. 2002

Evanson, N. K., Van Hooren, D. C., and Herman, J. P. (2009). GluR5mediated glutamate signaling regulates hypothalamo-pituitary-adrenocortical stress responses at the paraventricular nucleus and median eminence. Psychoneuroendocrinology 34, 1370-1379. doi: 10.1016/j.psyneuen.2009. 04.011

Faber, E. S., and Sah, P. (2003). Calcium-activated potassium channels: multiple contributions to neuronal function. Neuroscientist 9, 181-194. doi: 10.1177/ 1073858403009003011

Fagius, J. (2003). Sympathetic nerve activity in metabolic control-some basic concepts. Acta Physiol. Scand. 177, 337-343. doi: 10.1046/j.1365-201X.2003. 01086.x

Feetham, C., and Barrett-Jolley, R. (2014). Exploring thermosensitivity in the PVN. Proc. Physiol. Soc. 31:CB057. 
Feetham, C. H., Nunn, N., and Barrett-Jolley, R. (2015a). The depressor response to intracerebroventricular hypotonic saline is sensitive to TRPV4 antagonist RN1734. Front. Pharmacol. 6:83. doi: 10.3389/fphar.2015.00083

Feetham, C. H., Nunn, N., Lewis, R., Dart, C., and Barrett-Jolley, R. (2015b). TRPV4 and $\mathrm{KCa}$ ion channels functionally couple as osmosensors in the paraventricular nucleus. Br. J. Pharmacol. 172, 1753-1768. doi: 10.1111/bph. 13023

Ferguson, A. V., Latchford, K. J., and Samson, W. K. (2008). The paraventricular nucleus of the hypothalamus - a potential target for integrative treatment of autonomic dysfunction. Expert Opin. Ther. Targets 12, 717-727. doi: 10.1517/ 14728222.12.6.717

Flak, J. N., Myers, B., Solomon, M. B., McKlveen, J. M., Krause, E. G., and Herman, J. P. (2014). Role of paraventricular nucleus-projecting norepinephrine/epinephrine neurons in acute and chronic stress. Eur. J. Neurosci. 39, 1903-1911. doi: 10.1111/ejn.12587

Flak, J. N., Ostrander, M. M., Tasker, J. G., and Herman, J. P. (2009). Chronic stressinduced neurotransmitter plasticity in the PVN. J. Comp. Neurol. 517, 156-165. doi: $10.1002 /$ cne. 22142

Fontes, M. A., Tagawa, T., Polson, J. W., Cavanagh, S. J., and Dampney, R. A. (2001). Descending pathways mediating cardiovascular response from dorsomedial hypothalamic nucleus. AJP Heart Circ. Physiol. 280, H2891H2901. doi: 10.1152/ajpheart.2001.280.6.H2891

Fowler, M. A., Sidiropoulou, K., Ozkan, E. D., Phillips, C. W., and Cooper, D. C. (2007). Corticolimbic expression of TRPC4 and TRPC5 channels in the rodent brain. PLoS One 2:e573. doi: 10.1371/journal.pone.0000573

Fritschy, J.-M., and Mohler, H. (1995). GABA -receptor heterogeneity in the adult rat brain: differential regional and cellular distribution of seven major subunits. J. Comp. Neurol. 359, 154-194. doi: 10.1002/cne.903590111

Furuyama, T., Morita, Y., Inagaki, S., and Takagi, H. (1993). Distribution of I, II and III subtypes of voltage-sensitive $\mathrm{Na}+$ channel mRNA in the rat brain. Brain Res. Mol. Brain Res. 17, 169-173. doi: 10.1016/0169-328X(93)90087-6

Gao, F., and Wang, D. H. (2010). Hypotension induced by activation of the transient receptor potential vanilloid 4 channels: role of $\mathrm{Ca} 2+$-activated $\mathrm{K}+$ channels and sensory nerves. J. Hypertens. 28, 102-110. doi: 10.1097/HJH. 0b013e328332b865

Gao, H., Miyata, K., Bhaskaran, M. D., Derbenev, A. V., and Zsombok, A. (2012). Transient receptor potential vanilloid type 1-dependent regulation of liverrelated neurons in the paraventricular nucleus of the hypothalamus diminished in the type 1 diabetic mouse. Diabetes Metab. Res. Rev. 61, 1381-1390. doi: $10.2337 / \mathrm{db} 11-0820$

Gao, H., Molinas, A. J. R., Miyata, K., Qiao, X., and Zsombok, A. (2017). Overactivity of liver-related neurons in the paraventricular nucleus of the hypothalamus: electrophysiological findings in $\mathrm{db} / \mathrm{db}$ mice. J. Neurosci. 37, 11140-11150. doi: 10.1523/JNEUROSCI.1706-17.2017

Gao, S. F., Klomp, A., Wu, J. L., Swaab, D. F., and Bao, A. M. (2013). Reduced $\operatorname{GAD}(65 / 67)$ immunoreactivity in the hypothalamic paraventricular nucleus in depression: a postmortem study. J. Affect. Disord. 149, 422-425. doi: 10.1016/j. jad.2012.12.003

Garty, H., and Palmer, L. G. (1997). Epithelial sodium channels: function, structure, and regulation. Physiol. Rev. 77, 359-396. doi: 10.1152/physrev.1997.77.2.359

Geraldes, V., Goncalves-Rosa, N., Liu, B., Paton, J. F., and Rocha, I. (2014). Chronic depression of hypothalamic paraventricular neuronal activity produces sustained hypotension in hypertensive rats. Exp. Physiol. 99, 89-100. doi: 10.1113/expphysiol.2013.074823

Geraldes, V., Goncalves-Rosa, N., Tavares, C., Paton, J. F. R., and Rocha, I. (2016). Reversing gene expression in cardiovascular target organs following chronic depression of the paraventricular nucleus of hypothalamus and rostral ventrolateral medulla in spontaneous hypertensive rats. Brain Res. 1646, 109-115. doi: 10.1016/j.brainres.2016.05.041

Geraldes, V., Laranjo, S., and Rocha, I. (2018). Hypothalamic ion channels in hypertension. Curr. Hypertens. Rep. 20:14. doi: 10.1007/s11906-0180814-x

Glass, M. J., Wang, G., Coleman, C. G., Chan, J., Ogorodnik, E., Van Kempen, T. A., et al. (2015). NMDA receptor plasticity in the hypothalamic paraventricular nucleus contributes to the elevated blood pressure produced by angiotensin II. J. Neurosci. 35, 9558-9567. doi: 10.1523/JNEUROSCI.2301-14.2015

Guggilam, A., Cardinale, J. P., Mariappan, N., Sriramula, S., Haque, M., and Francis, J. (2011). Central TNF inhibition results in attenuated neurohumoral excitation in heart failure: a role for superoxide and nitric oxide. Basic Res. Cardiol. 106, 273-286. doi: 10.1007/s00395-010-0146-8

Guggilam, A., Haque, M., Kerut, E. K., McIlwain, E., Lucchesi, P., Seghal, I., et al. (2007). TNF-alpha blockage decreases oxidative stress in the paraventricular nucleus and attenuates sympathoexcitation in heart failure rats. Am. J. Physiol. Heart Circ. Physiol. 293, H599-H609. doi: 10.1152/ajpheart.00286.2007

Guggilam, A., Patel, K. P., Masudul, H., Ebenezer, P. J., Kapusta, D. R., and Francis, J. (2008). Cytokine blockade attenuates sympathoexcitation in heart failure: cross-talk between nNOS, AT-1R and cytokines in the hypothalamic paraventricular nucleus. Eur. J. Heart Fail. 10, 625-634. doi: 10.1016/j.ejheart. 2008.05.004

Gui, L., LaGrange, L. P., Larson, R. A., Gu, M., Zhu, J., and Chen, Q. H. (2012). Role of small conductance calcium-activated potassium channels expressed in PVN in regulating sympathetic nerve activity and arterial blood pressure in rats. Am. J. Physiol. Regul. Integr. Comp. Physiol. 303, R301-R310. doi: 10.1152/ajpregu. 00114.2012

Guilak, F., Leddy, H. A., and Liedtke, W. (2010). Transient receptor potential vanilloid 4: the sixth sense of the musculoskeletal system? Ann. N. Y. Acad. Sci. 1192, 404-409. doi: 10.1111/j.1749-6632.2010.05389.x

Guo, W., Sun, J., Xu, X., Bunstock, G., He, C., and Xiang, Z. (2009). P2X receptors are differentially expressed on vasopressin- and oxytocin-containing neurons in the supraoptic and paraventricular nuclei of rat hypothalamus. Histochem. Cell Biol. 131, 29-41. doi: 10.1007/s00418-008-0493-9

Guyenet, P. G. (2006). The sympathetic control of blood pressure. Nat. Rev. Neurosci. 7, 335-346. doi: 10.1038/nrn1902

Han, J., Gnatenco, C., Sladek, C. D., and Kim, D. (2003). Background and tandem-pore potassium channels in magnocellular neurosecretory cells of the rat supraoptic nucleus. J. Physiol. 546, 625-639. doi: 10.1113/jphysiol.2002. 032094

Herman, J. P., and Cullinan, W. E. (1997). Neurocircuitry of stress: central control of the hypothalamo-pituitary-adrenocortical axis. Trends Neurosci. 20, 78-84. doi: 10.1016/S0166-2236(96)10069-2

Hermes, M. L., Buijs, R. M., and Renaud, L. P. (1996a). Electrophysiology of suprachiasmatic nucleus projections to hypothalamic paraventricular nucleus neurons. Prog. Brain Res. 111, 241-252. doi: 10.1016/S0079-6123(08) 60412-4

Hermes, M. L., Coderre, E. M., Buijs, R. M., and Renaud, L. P. (1996b). GABA and glutamate mediate rapid neurotransmission from suprachiasmatic nucleus to hypothalamic paraventricular nucleus in rat. J. Physiol. 496, 749-757.

Hervieu, G. J., Cluderay, J. E., Gray, C. W., Green, P. J., Ranson, J. L., Randall, A. D., et al. (2001). Distribution and expression of TREK-1, a two-poredomain potassium channel, in the adult rat CNS. Neuroscience 103, 899-919. doi: 10.1016/S0306-4522(01)00030-6

Hetzenauer, A., Sinnegger-Brauns, M. J., Striessnig, J., and Singewald, N. (2006). Brain activation pattern induced by stimulation of L-type Ca2+-channels: contribution of $\mathrm{Ca}(\mathrm{V}) 1.3$ and $\mathrm{Ca}(\mathrm{V}) 1.2$ isoforms. Neuroscience $139,1005-1015$. doi: 10.1016/j.neuroscience.2006.01.059

Hille, B. (1986). Ionic channels: molecular pores of excitable membranes. Harvey Lect. 82, 47-69.

Hille, B. (1994). Modulation of ion-channel function by G-protein-coupled receptors. Trends Neurosci. 17, 531-536. doi: 10.1016/0166-2236(94) 90157-0

Hindmarch, C., Yao, S., Beighton, G., Paton, J., and Murphy, D. (2006). A comprehensive description of the transcriptome of the hypothalamoneurohypophyseal system in euhydrated and dehydrated rats. Proc. Natl. Acad. Sci. U.S.A. 103, 1609-1614. doi: 10.1073/pnas.050745 0103

Hodgkin, A. L., and Huxley, A. F. (1952). A quantitative description of membrane current and its application to conduction and excitation in nerve. J. Physiol. 117, 500-544. doi: 10.1113/jphysiol.1952.sp004764

Hoffman, N. W., Tasker, J. G., and Dudek, F. E. (1991). Immunohistochemical differentiation of electrophysiologically defined neuronal populations in the region of the rat hypothalamic paraventricular nucleus. J. Comp. Neurol. 307, 405-416. doi: 10.1002/cne.903070306

Holbein, W. W., Bardgett, M. E., and Toney, G. M. (2014). Blood pressure is maintained during dehydration by hypothalamic paraventricular nucleus driven tonic sympathetic nerve activity. J. Physiol. 592, 3783-3799. doi: 10.1113/ jphysiol.2014.276261 
Hoshikawa, M., Kato, A., Hojo, H., Shibata, Y., Kumamoto, N., Watanabe, M., et al. (2017). Distribution of ASIC4 transcripts in the adult wild-type mouse brain. Neurosci. Lett. 651, 57-64. doi: 10.1016/j.neulet.2017.03.054

Hosoya, Y., Sugiura, Y., Okado, N., Loewy, A. D., and Kohno, K. (1991). Descending input from the hypothalamic paraventricular nucleus to sympathetic preganglionic neurons in the rat. Exp. Brain Res. 85, 10-20. doi: 10.1007/BF00229982

Humphries, E. S., and Dart, C. (2015). Neuronal and cardiovascular potassium channels as therapeutic drug targets: promise and pitfalls. J. Biomol. Screen. 20, 1055-1073. doi: 10.1177/1087057115601677

Inenaga, K., Osaka, T., and Yamashita, H. (1987). Thermosensitivity of neurons in the paraventricular nucleus of the rat slice preparation. Brain Res. 424, 126-132. doi: 10.1016/0006-8993(87)91201-7

Jansen, A. S., Nguyen, X. V., Karpitskiy, V., Mettenleiter, T. C., and Loewy, A. D. (1995). Central command neurons of the sympathetic nervous system: basis of the fight-or-flight response. Science 270, 644-646. doi: 10.1126/science.270. 5236.644

Jarnot, M., and Corbett, A. M. (2006). Immunolocalization of Nav1.2 channel subtypes in rat and cat brain and spinal cord with high affinity antibodies. Brain Res. 1107, 1-12. doi: 10.1016/j.brainres.2006.05.090

Jones, S. W. (1987). A muscarine-resistant M-current in C cells of bullfrog sympathetic ganglia. Neurosci. Lett. 74, 309-314. doi: 10.1016/0304-3940(87) 90315-6

Kadar, A., Sanchez, E., Wittmann, G., Singru, P. S., Fuzesi, T., Marsili, A., et al. (2010). Distribution of hypophysiotropic thyrotropin-releasing hormone (TRH)-synthesizing neurons in the hypothalamic paraventricular nucleus of the mouse. J. Comp. Neurol. 518, 3948-3961. doi: 10.1002/cne.22432

Kalsbeek, A., Fliers, E., Franke, A. N., Wortel, J., and Buijs, R. M. (2000). Functional connections between the suprachiasmatic nucleus and the thyroid gland as revealed by lesioning and viral tracing techniques in the rat. Endocrinology 141, 3832-3841. doi: 10.1210/endo.141.10.7709

Kalsbeek, A., La Fleur, S., Van Heijningen, C., and Buijs, R. M. (2004). Suprachiasmatic GABAergic inputs to the paraventricular nucleus control plasma glucose concentrations in the rat via sympathetic innervation of the liver. J. Neurosci. 24, 7604-7613. doi: 10.1523/JNEUROSCI.532803.2004

Kannan, H., Hayashida, Y., and Yamashita, H. (1989). Increase in sympathetic outflow by paraventricular nucleus stimulation in awake rats 1. Am. J. Physiol. 256, R1325-R1330. doi: 10.1152/ajpregu.1989.256.6.R1325

Kawabe, T., Chitrauanshi, V. C., Nakamura, T., Kawabe, K., and Sapru, H. N. (2009). Mechanism of heart rate responses elicited by chemical stimulation of the hypothalamic paraventricular nucleus in the rat. Brain Res. 1248, 115-126. doi: 10.1016/j.brainres.2008.10.059

Kiss, J., Martos, J., and Palkovits, M. (1991). Hypothalamic paraventricular nucleus: a quantitative analysis of cytoarchitectonic subdivisions in the rat. J. Comp. Neurol. 313, 563-573. doi: 10.1002/cne.903130403

Kohler, M., Hirschberg, B., Bond, C. T., Kinzie, J. M., Marrion, N. V., Maylie, J., et al. (1996). Small-conductance, calcium-activated potassium channels from mammalian brain. Science 273, 1709-1714. doi: 10.1126/science.273.5282.1709

Koutcherov, Y., Mai, J., Ashwell, K., and Paxinos, G. (2000). Organization of the human paraventricular hypothalamic nucleus. J. Comp. Neurol. 423, 299-318. doi: 10.1002/1096-9861(20000724)423:2<299::AID-CNE8>3.0.CO;2-A

Kubo, Y., Baldwin, T. J., Jan, Y. N., and Jan, L. Y. (1993). Primary structure and functional expression of a mouse inward rectifier potassium channel. Nature 362, 127-133. doi: 10.1038/362127a0

Kumar, S., Singh, U., Goswami, C., and Singru, P. S. (2017). Transient receptor potential vanilloid 5 (TRPV5), a highly $\mathrm{Ca}^{2+}$-selective TRP channel in the rat brain: relevance to neuroendocrine regulation. J. Neuroendocrinol. 29, 1-23. doi: 10.1111/jne. 12466

la Fleur, S. E., Kalsbeek, A., Wortel, J., and Buijs, R. M. (2000). Polysynaptic neural pathways between the hypothalamus, including the suprachiasmatic nucleus, and the liver. Brain Res. 871, 50-56. doi: 10.1016/S0006-8993(00)02 423-9

Latchford, K. J., and Ferguson, A. V. (2005). Angiotensin depolarizes parvocellular neurons in paraventricular nucleus through modulation of putative nonselective cationic and potassium conductances. Am. J. Physiol. Regul. Integr. Comp. Physiol. 289, R52-R58. doi: 10.1152/ajpregu.00549. 2004
Lee, S., Han, T. H., Sonner, P. M., Stern, J. E., Ryu, P. D., and Lee, S. Y. (2008). Molecular characterization of T-type $\mathrm{Ca}(2+)$ channels responsible for low threshold spikes in hypothalamic paraventricular nucleus neurons. Neuroscience 155, 1195-1203. doi: 10.1016/j.neuroscience.2008.06.055

Lee, S. K., Lee, S., Shin, S. Y., Ryu, P. D., and Lee, S. Y. (2012). Single cell analysis of voltage-gated potassium channels that determines neuronal types of rat hypothalamic paraventricular nucleus neurons. Neuroscience 205, 49-62. doi: 10.1016/j.neuroscience.2011.12.031

Leibowitz, S. F., Akabayashi, A., Wang, J., Alexander, J. T., Dourmashkin, J. T., and Chang, G. Q. (2007). Increased caloric intake on a fat-rich diet: role of ovarian steroids and galanin in the medial preoptic and paraventricular nuclei and anterior pituitary of female rats. J. Neuroendocrinol. 19, 753-766. doi: 10.1111/j.1365-2826.2007.01584.x

Leite, L. H., Zheng, H., Coimbra, C. C., and Patel, K. P. (2012). Contribution of the paraventricular nucleus in autonomic adjustments to heat stress. Exp. Biol. Med. 237, 570-577. doi: 10.1258/ebm.2011.011286

Levin, B. E., Routh, V. H., Kang, L., Sanders, N. M., and Dunn-Meynell, A. A. (2004). Neuronal glucosensing: what do we know after 50 years? Diabetes 53 , 2521-2528.

Lewis, R., Mills, A. F., and Barrett-Jolley, R. (2010). Models of paraventricular nucleus (PVN) sympathetic neurone modulation by glucose and hypoglycaemia. Biophys. J. 98:140a. doi: 10.1016/j.bpj.2009.12.756

Li, D. P., Chen, S. R., Finnegan, T. F., and Pan, H. L. (2004a). Signalling pathway of nitric oxide in synaptic GABA release in the rat paraventricular nucleus. J. Physiol. 554, 100-110.

Li, D. P., Chen, S. R., and Pan, H. L. (2004b). VR1 receptor activation induces glutamate release and postsynaptic firing in the paraventricular nucleus. J. Neurophysiol. 92, 1807-1816.

Li, D. P., Chen, S. R., and Pan, H. L. (2002). Nitric oxide inhibits spinally projecting paraventricular neurons through potentiation of presynaptic GABA release. J. Neurophysiol. 88, 2664-2674. doi: 10.1152/jn.00540.2002

Li, D. P., Chen, S. R., and Pan, H. L. (2003). Angiotensin II stimulates spinally projecting paraventricular neurons through presynaptic disinhibition. J. Neurosci. 23, 5041-5049. doi: 10.1523/JNEUROSCI.23-12-05041.2003

Li, D. P., Chen, S. R., and Pan, H. L. (2010). Adenosine inhibits paraventricular pre-sympathetic neurons through ATP-dependent potassium channels. J. Neurochem. 113, 530-542. doi: 10.1111/j.1471-4159.2010.06618.x

Li, D. P., Zhu, L. H., Pachuau, J., Lee, H. A., and Pan, H. L. (2014). mGluR5 Upregulation increases excitability of hypothalamic presympathetic neurons through NMDA receptor trafficking in spontaneously hypertensive rats. J. Neurosci. 34, 4309-4317. doi: 10.1523/JNEUROSCI.4295-13.2014

Li, H. S., Xu, X. Z., and Montell, C. (1999). Activation of a TRPC3-dependent cation current through the neurotrophin BDNF. Neuron 24, 261-273. doi: 10.1016/S0896-6273(00)80838-7

Li, W., Feng, Z., Sternberg, P. W., and Xu, X. Z. (2006). A C. Elegans stretch receptor neuron revealed by a mechanosensitive TRP channel homologue. Nature 440, 684-687. doi: 10.1038/nature04538

Li, Y. F., and Patel, K. P. (2003). Paraventricular nucleus of the hypothalamus and elevated sympathetic activity in heart failure: the altered inhibitory mechanisms. Acta Physiol. Scand. 177, 17-26. doi: 10.1046/j.1365-201X.2003. 01043.x

Liman, E. R. (2014). Trpm5. Handb. Exp. Pharmacol. 222, 489-502. doi: 10.1007/ 978-3-642-54215-2_19

Lovick, T. A., and Coote, J. H. (1988). Effects of volume loading on paraventriculospinal neurones in the rat. J. Auton. Nerv. Syst. 25, 135-140. doi: 10.1016/01651838(88)90018-5

Lovick, T. A., and Coote, J. H. (1989). Circulating atrial natriuretic factor activates vagal afferent inputs to paraventriculo-spinal neurones in the rat. J. Auton. Nerv. Syst. 26, 129-134. doi: 10.1016/0165-1838(89)90161-6

Lovick, T. A., Malpas, S., and Mahony, M. T. (1993). Renal vasodilatation in response to acute volume load is attenuated following lesions of parvocellular neurones in the paraventricular nucleus in rats. J. Auton. Nerv. Syst. 43, 247-256. doi: 10.1016/0165-1838(93)90331-N

Luther, J. A., Daftary, S. S., Boudaba, C., Gould, G. C., Halmos, K. C., and Tasker, J. G. (2002). Neurosecretory and non-neurosecretory parvocellular neurones of the hypothalamic paraventricular nucleus express distinct electrophysiological properties. J. Neuroendocrinol. 14, 929-932. doi: 10.1046/j.1365-2826.2002. 00867.x 
Luther, J. A., and Tasker, J. G. (2000). Voltage-gated currents distinguish parvocellular from magnocellular neurones in the rat hypothalamic paraventricular nucleus. J. Physiol. 523, 193-209. doi: 10.1111/j.1469-7793. 2000.t01-1-00193.x

Maingret, F., Lauritzen, I., Patel, A. J., Heurteaux, C., Reyes, R., Lesage, F., et al. (2000). TREK-1 is a heat-activated background $\mathrm{K}(+)$ channel. EMBO J. 19, 2483-2491. doi: 10.1093/emboj/19.11.2483

Manaye, K. F., Lei, D. L., Tizabi, Y., Davila-Garcia, M. I., Mouton, P. R., and Kelly, P. H. (2005). Selective neuron loss in the paraventricular nucleus of hypothalamus in patients suffering from major depression and bipolar disorder. J. Neuropathol. Exp. Neurol. 64, 224-229. doi: 10.1093/jnen/64.3.224

Martin, D. S., and Haywood, J. R. (1992). Sympathetic nervous-system activation by glutamate injections into the paraventricular nucleus. Brain Res. 577, 261-267. doi: 10.1016/0006-8993(92)90282-E

Martin, D. S., and Haywood, J. R. (1993). Hemodynamic responses to paraventricular nucleus disinhibition with bicuculline in conscious rats. Am. J. Physiol. 265, H1727-H1733. doi: 10.1152/ajpheart.1993.265.5.H1727

Martin, D. S., Segura, T., and Haywood, J. R. (1991). Cardiovascular responses to bicuculline in the paraventricular nucleus of the rat. Hypertension 18, 48-55. doi: 10.1161/01.HYP.18.1.48

Mason, W. T. (1980). Supraoptic neurones of rat hypothalamus are osmosensitive. Nature 287, 154-157. doi: 10.1038/287154a0

Mathar, I., Jacobs, G., Kecskes, M., Menigoz, A., Philippaert, K., and Vennekens, R. (2014). Trpm4. Handb. Exp. Pharmacol. 222, 461-487. doi: 10.1007/978-3-64254215-2_18

Medhurst, A. D., Rennie, G., Chapman, C. G., Meadows, H., Duckworth, M. D., Kelsell, R. E., et al. (2001). Distribution analysis of human two pore domain potassium channels in tissues of the central nervous system and periphery. Brain Res. Mol. Brain Res. 86, 101-114. doi: 10.1016/S0169-328X(00) 00263-1

Melnick, I. V., Price, C. J., and Colmers, W. F. (2011). Glucosensing in parvocellular neurons of the rat hypothalamic paraventricular nucleus. Eur. J. Neurosci. 34, 272-282. doi: 10.1111/j.1460-9568.2011.07742.x

Meng, Q. Y., Wang, W., Chen, X. N., Xu, T. L., and Zhou, J. N. (2009). Distribution of acid-sensing ion channel 3 in the rat hypothalamus. Neuroscience 159, 1126-1134. doi: 10.1016/j.neuroscience.2009.01.069

Molinarolo, S., Granata, D., Carnevale, V., and Ahern, C. A. (2018). Mining protein evolution for insights into mechanisms of voltage-dependent sodium channel auxiliary subunits. Handb. Exp. Pharmacol. 246, 33-49. doi: 10.1007/164 _2017_75

Monteggia, L. M., Eisch, A. J., Tang, M. D., Kaczmarek, L. K., and Nestler, E. J. (2000). Cloning and localization of the hyperpolarization-activated cyclic nucleotide-gated channel family in rat brain. Mol. Brain Res. 81, 129-139. doi: 10.1016/S0169-328X(00)00155-8

Morishige, K. I., Inanobe, A., Takahashi, N., Yoshimoto, Y., Kurachi, H., Miyake, A., et al. (1996). G protein-gated K+ channel (GIRK1) protein is expressed presynaptically in the paraventricular nucleus of the hypothalamus. Biochem. Biophys. Res. Commun. 220, 300-305. doi: 10.1006/bbrc.1996. 0400

Myers, B., McKlveen, J. M., and Herman, J. P. (2012). Neural regulation of the stress response: the many faces of feedback. Cell. Mol. Neurobiol. [Epub ahead of print]. doi: 10.1007/s10571-012-9801-y

Nedungadi, T. P., and Cunningham, J. T. (2014). Differential regulation of TRPC4 in the vasopressin magnocellular system by water deprivation and hepatic cirrhosis in the rat. Am. J. Physiol. Regul. Integr. Comp. Physiol. 306, R304-R314. doi: 10.1152/ajpregu.00388.2013

Nedungadi, T. P., Dutta, M., Bathina, C. S., Caterina, M. J., and Cunningham, J. T. (2012). Expression and distribution of TRPV2 in rat brain. Exp. Neurol. 237, 223-237. doi: 10.1016/j.expneurol.2012.06.017

Nichols, C. G. (2006). K-ATP channels as molecular sensors of cellular metabolism. Nature 440, 470-476. doi: 10.1038/nature04711

Nichols, C. G., and Lopatin, A. N. (1997). Inward rectifier potassium channels. Annu. Rev. Physiol. 59, 171-191. doi: 10.1146/annurev.physiol.59. 1.171

Nilius, B., Prenen, J., Droogmans, G., Voets, T., Vennekens, R., Freichel, M., et al. (2003). Voltage dependence of the Ca2+-activated cation channel TRPM4. J. Biol. Chem. 278, 30813-30820. doi: 10.1074/jbc.M30512 7200
Nunn, N., Womack, M., Dart, C., and Barrett-Jolley, R. (2011). Function and pharmacology of spinally-projecting sympathetic pre-autonomic neurones in the paraventricular nucleus of the hypothalamus. Curr. Neuropharmacol. 9, 262-277. doi: 10.2174/157015911795596531

O’Hare, J. D., and Zsombok, A. (2016). Brain-liver connections: role of the preautonomic PVN neurons. Am. J. Physiol. Endocrinol. Metab. 310, E183-E189. doi: 10.1152/ajpendo.00302.2015

Oldfield, B. J., Davern, P. J., Giles, M. E., Allen, A. M., Badoer, E., and McKinley, M. J. (2001). Efferent neural projections of angiotensin receptor (AT1) expressing neurones in the hypothalamic paraventricular nucleus of the rat. J. Neuroendocrinol. 13, 139-146. doi: 10.1046/j.1365-2826.2001. 00597.x

Pachuau, J., Li, D. P., Chen, S. R., Lee, H. A., and Pan, H. L. (2014). Protein kinase CK2 contributes to diminished small conductance $\mathrm{Ca}$-activated $\mathrm{K}$ channel activity of hypothalamic pre-sympathetic neurons in hypertension. J. Neurochem. 130, 657-667. doi: 10.1111/jnc. 12758

Pan, H., Guo, J., and Su, Z. (2014). Advances in understanding the interrelations between leptin resistance and obesity. Physiol. Behav. 130, 157-169. doi: 10.1016/j.physbeh.2014.04.003

Patel, K. P. (1997). Neural regulation in experimental heart failure. Baillieres Clin. Neurol. 6, 285-296.

Paxinos, G., and Watson, C. (1986). The Rat Brain in Stereotaxic Coordinates. Cambridge: Academic Press.

Perez, C. A., Huang, L., Rong, M., Kozak, J. A., Preuss, A. K., Zhang, H., et al. (2002). A transient receptor potential channel expressed in taste receptor cells. Nat. Neurosci. 5, 1169-1176. doi: 10.1038/nn952

Perez-Reyes, E. (1999). Three for T: molecular analysis of the low voltageactivated calcium channel family. Cell. Mol. Life Sci. 56, 660-669. doi: 10.1007/ s000180050460

Perez-Reyes, E. (2003). Molecular physiology of low-voltage-activated T-type calcium channels. Physiol. Rev. 83, 117-161. doi: 10.1152/physrev.00018.2002

Powis, J. E., Bains, J. S., and Ferguson, A. V. (1998). Leptin depolarizes rat hypothalamic paraventricular nucleus neurons. Am. J. Physiol. Regul. Integr. Comp. Physiol. 274, R1468-R1472. doi: 10.1152/ajpregu.1998.274.5.R1468

Pyner, S. (2009). Neurochemistry of the paraventricular nucleus of the hypothalamus: implications for cardiovascular regulation. J. Chem. Neuroanat. 38, 197-208. doi: 10.1016/j.jchemneu.2009.03.005

Pyner, S. (2014). The paraventricular nucleus and heart failure. Exp. Physiol. 99, 332-339. doi: 10.1113/expphysiol.2013.072678

Pyner, S., and Coote, J. H. (2000). Identification of branching paraventricular neurons of the hypothalamus that project to the rostroventrolateral medulla and spinal cord. Neuroscience 100, 549-556. doi: 10.1016/S0306-4522(00)00283-9

Pyner, S., Deering, J., and Coote, J. H. (2002). Right atrial stretch induces renal nerve inhibition and $\mathrm{c}$-fos expression in parvocellular neurones of the paraventricular nucleus in rats. Exp. Physiol. 87, 25-32. doi: 10.1113/ eph8702279

Raadsheer, F. C., Sluiter, A. A., Ravid, R., Tilders, F. J., and Swaab, D. F. (1993). Localization of corticotropin-releasing hormone (CRH) neurons in the paraventricular nucleus of the human hypothalamus; age-dependent colocalization with vasopressin. Brain Res. 615, 50-62. doi: 10.1016/00068993(93)91113-7

Roberts, J. C., Davis, J. B., and Benham, C. D. (2004). [3H]Resiniferatoxin autoradiography in the CNS of wild-type and TRPV1 null mice defines TRPV1 (VR-1) protein distribution. Brain Res. 995, 176-183. doi: 10.1016/j.brainres. 2003.10.001

Saenz del Burgo, L., Cortes, R., Mengod, G., Zarate, J., Echevarria, E., and Salles, J. (2008). Distribution and neurochemical characterization of neurons expressing GIRK channels in the rat brain. J. Comp. Neurol. 510, 581-606. doi: 10.1002/ cne. 21810

Sah, P. (1996). Ca(2+)-activated $\mathrm{K}+$ currents in neurones: types, physiological roles and modulation. Trends Neurosci. 19, 150-154. doi: 10.1016/S01662236(96)80026-9

Salzmann, M., Seidel, K. N., Bernard, R., Pruss, H., Veh, R. W., and Derst, C. (2010). BKbetal subunits contribute to BK channel diversity in rat hypothalamic neurons. Cell. Mol. Neurobiol. 30, 967-976. doi: 10.1007/s10571-0109527-7

Sausbier, U., Sausbier, M., Sailer, C. A., Arntz, C., Knaus, H. G., Neuhuber, W., et al. (2006). Ca2+-activated $\mathrm{K}+$ channels of the BK-type in the 
mouse brain. Histochem. Cell Biol. 125, 725-741. doi: 10.1007/s00418-0050124-7

Schlenker, E., Barnes, L., Hansen, S., and Martin, D. (2001). Cardiorespiratory and metabolic responses to injection of bicuculline into the hypothalamic paraventricular nucleus (PVN) of conscious rats. Brain Res. 895, 33-40. doi: 10.1016/S0006-8993(01)02011-X

Shafton, A. D., Ryan, A., and Badoer, E. (1998). Neurons in the hypothalamic paraventricular nucleus send collaterals to the spinal cord and to the rostral ventrolateral medulla in the rat. Brain Res. 801, 239-243. doi: 10.1016/S00068993(98)00587-3

Shi, Y. C., Lau, J., Lin, Z., Zhang, H., Zhai, L., Sperk, G., et al. (2013). Arcuate NPY controls sympathetic output and BAT function via a relay of tyrosine hydroxylase neurons in the PVN. Cell Metab. 17, 236-248. doi: 10.1016/j.cmet. 2013.01.006

Shimada, O., and Ishikawa, H. (1989). Somatostatin-containing neurons in the mouse brain: an immunohistochemical study and comparison with the rat brain. Arch. Histol. Cytol. 52, 201-212. doi: 10.1679/aohc. 52.201

Shiraishi, T. (1987). Gastric related properties of rat paraventricular neurons. Brain Res. Bull. 18, 315-323. doi: 10.1016/0361-9230(87) 90009-8

Shirasaka, T., Kannan, H., and Takasaki, M. (2007). Activation of a G protein-coupled inwardly rectifying $\mathrm{K}+$ current and suppression of $\mathrm{Ih}$ contribute to dexmedetomidine-induced inhibition of rat hypothalamic paraventricular nucleus neurons. Anesthesiology 107, 605-615. doi: 10.1097/01. anes.0000281916.65365.4e

Simmons, D. M., and Swanson, L. W. (2008). High-resolution paraventricular nucleus serial section model constructed within a traditional rat brain atlas. Neurosci. Lett. 438, 85-89. doi: 10.1016/j.neulet.2008. 04.057

Sonner, P. M., Filosa, J. A., and Stern, J. E. (2008). Diminished A-type potassium current and altered firing properties in presympathetic PVN neurones in renovascular hypertensive rats. J. Physiol. 586, 1605-1622. doi: 10.1113/jphysiol. 2007.147413

Sonner, P. M., Lee, S., Ryu, P. D., Lee, S. Y., and Stern, J. E. (2011). Imbalanced $\mathrm{K}+$ and $\mathrm{Ca} 2+$ subthreshold interactions contribute to increased hypothalamic presympathetic neuronal excitability in hypertensive rats. J. Physiol. 589, 667-683. doi: 10.1113/jphysiol.2010.198556

Sonner, P. M., and Stern, J. E. (2005). Role of A-type potassium currents on the excitability and firing activity of RVLM-projecting PVN neurons. FASEB J. 19:A599.

Sonner, P. M., and Stern, J. E. (2007). Functional role of A-type potassium currents in rat presympathetic PVN neurones. J. Physiol. 582, 1219-1238. doi: 10.1113/ jphysiol.2007.134379

Stafstrom, C. E. (2007). Persistent sodium current and its role in epilepsy. Epilepsy Curr. 7, 15-22. doi: 10.1111/j.1535-7511.2007.00156.x

Stanfield, P. R., Nakajima, Y., and Yamaguchi, K. (1985). Substance P raises neuronal membrane excitability by reducing inward rectification. Nature 315 , 498-501. doi: 10.1038/315498a0

Stanley, S., Pinto, S., Segal, J., Perez, C. A., Viale, A., DeFalco, J., et al. (2010). Identification of neuronal subpopulations that project from hypothalamus to both liver and adipose tissue polysynaptically. Proc. Natl. Acad. Sci. U.S.A. 107, 7024-7029. doi: 10.1073/pnas.1002790107

Stern, J. E. (2001). Electrophysiological and morphological properties of preautonomic neurones in the rat hypothalamic paraventricular nucleus. J. Physiol. 537, 161-177. doi: 10.1111/j.1469-7793.2001.0161k.x

Stonehouse, A. H., Pringle, J. H., Norman, R. I., Stanfield, P. R., Conley, E. C., and Brammar, W. J. (1999). Co-localization of the inwardly rectifying potassium ion channel, Kir2.2, and the substance P receptor in single locus coeruleus neurons. Ann. N. Y. Acad. Sci. 897, 429-431. doi: 10.1111/j.1749-6632.1999.tb0 7913.x

Swanson, L., and Kuypers, H. (1980). The paraventricular nucleus of the hypothalamus: cytoarchitectonic subdivisions and organization of projections to the pituitary, dorsal vagal complex, and spinal cord as demonstrated by retrograde fluorescence double-labeling methods. J. Comp. Neurol. 194, 555-570. doi: 10.1002/cne.901940306

Swanson, L. W., and Sawchenko, P. E. (1980). Paraventricular nucleus: a site for the integration of neuroendocrine and autonomic mechanisms. Neuroendocrinology 31, 410-417. doi: 10.1159/00012 3111

Swanson, L. W., and Sawchenko, P. E. (1983). Hypothalamic integration organization of the paraventricular and supraoptic nuclei. Annu. Rev. Neurosci. 6, 269-324. doi: 10.1146/annurev.ne.06.030183.001413

Swanson, L. W., Sawchenko, P. E., Wiegand, S. J., and Price, J. L. (1980). Separate neurons in the paraventricular nucleus project to the median-eminence and to the medulla or spinal-cord. Brain Res. 198, 190-195. doi: 10.1016/00068993(80)90354-6

Takeda, K., Nakata, T., Takesako, T., Itoh, H., Hirata, M., Kawasaki, S., et al. (1991). Sympathetic inhibition and attenuation of spontaneous hypertension by Pvn lesions in rats. Brain Res. 543, 296-300. doi: 10.1016/0006-8993(91)9 0040-3

Tasker, J. G., and Dudek, F. E. (1991). Electrophysiological properties of neurones in the region of the paraventricular nucleus in slices of rat hypothalamus. J. Physiol. 434, 271-293. doi: 10.1113/jphysiol.1991.sp01 8469

Tasker, J. G., and Dudek, F. E. (1993). Local inhibitory synaptic inputs to neurones of the paraventricular nucleus in slices of rat hypothalamus. J. Physiol. 469, 179-192. doi: 10.1113/jphysiol.1993.sp019810

Teruyama, R., Sakuraba, M., Kurotaki, H., and Armstrong, W. E. (2011). Transient receptor potential channel $\mathrm{m} 4$ and $\mathrm{m} 5$ in magnocellular cells in rat supraoptic and paraventricular nuclei. J. Neuroendocrinol. 23, 1204-1213. doi: 10.1111/j. 1365-2826.2011.02211.x

Teruyama, R., Sakuraba, M., Wilson, L. L., Wandrey, N. E., and Armstrong, W. E. (2012). Epithelial $\mathrm{Na}(+)$ sodium channels in magnocellular cells of the rat supraoptic and paraventricular nuclei. Am. J. Physiol. Endocrinol. Metab. 302, E273-E285. doi: 10.1152/ajpendo.00407.2011

van den Burg, E. H., Stindl, J., Grund, T., Neumann, I. D., and Strauss, O. (2015). Oxytocin stimulates extracellular Ca2+ influx through TRPV2 channels in hypothalamic neurons to exert its anxiolytic effects. Neuropsychopharmacology 40, 2938-2947. doi: 10.1038/npp.2015.147

Van Huysse, J. W., Amin, M. S., Yang, B., and Leenen, F. H. (2012). Saltinduced hypertension in a mouse model of Liddle syndrome is mediated by epithelial sodium channels in the brain. Hypertension 60, 691-696. doi: 10.1161/ HYPERTENSIONAHA.112.193045

Varghese, F. P., and Brown, E. S. (2001). The hypothalamic-pituitary-adrenal axis in major depressive disorder: a brief primer for primary care physicians. Prim. Care Companion J. Clin. Psychiatry 3, 151-155. doi: 10.4088/PCC.v03n0401

Vergara, C., Latorre, R., Marrion, N. V., and Adelman, J. P. (1998). Calciumactivated potassium channels. Curr. Opin. Neurobiol. 8, 321-329. doi: 10.1016/ S0959-4388(98)80056-1

Waki, H., Gouraud, S. S., Maeda, M., and Paton, J. F. (2008). Gene expression profiles of major cytokines in the nucleus tractus solitarii of the spontaneously hypertensive rat. Auton. Neurosci. 142, 40-44. doi: 10.1016/j.autneu.2008. 07.001

Wang, H. W., Amin, M. S., El-Shahat, E., Huang, B. S., Tuana, B. S., and Leenen, F. H. (2010). Effects of central sodium on epithelial sodium channels in rat brain. Am. J. Physiol. Regul. Integr. Comp. Physiol. 299, R222-R233. doi: 10.1152/ajpregu.00834.2009

Wang, R. J., Zeng, Q. H., Wang, W. Z., and Wang, W. (2009). GABA(A) and $G A B A(B)$ receptor-mediated inhibition of sympathetic outflow in the paraventricular nucleus is blunted in chronic heart failure. Clin. Exp. Pharmacol. Physiol. 36, 516-522. doi: 10.1111/j.1440-1681.2008.05101.x

Watkins, N. D., Cork, S. C., and Pyner, S. (2009). An immunohistochemical investigation of the relationship between neuronal nitric oxide synthase, GABA and presympathetic paraventricular neurons in the hypothalamus. Neuroscience 159, 1079-1088. doi: 10.1016/j.neuroscience.2009.01.012

Wellman, G. C., Barrett-Jolley, R., Koppel, H., Everitt, D., and Quayle, J. M. (1999). Inhibition of vascular K-ATP channels by U-37883A: a comparison with cardiac and skeletal muscle. Br. J. Pharmacol. 128, 909-916. doi: 10.1038/sj.bjp.0702868

Westenbroek, R. E., Merrick, D. K., and Catterall, W. A. (1989). Differential subcellular localization of the RI and RII Na+ channel subtypes in central neurons. Neuron 3, 695-704. doi: 10.1016/0896-6273(89)90238-9

Whitaker, W. R., Faull, R. L., Waldvogel, H. J., Plumpton, C. J., Emson, P. C., and Clare, J. J. (2001). Comparative distribution of voltage-gated sodium channel proteins in human brain. Brain Res. Mol. Brain Res. 88, 37-53. doi: 10.1016/ S0169-328X(00)00289-8 
Womack, M. D., and Barrett-Jolley, R. (2007). Activation of paraventricular nucleus neurones by the dorsomedial hypothalamus via a tachykinin pathway in rats. Exp. Physiol. 92, 671-676. doi: 10.1113/expphysiol.2007. 037457

Womack, M. D., Morris, R., Gent, T. C., and Barrett-Jolley, R. (2007). Substance $\mathrm{P}$ targets sympathetic control neurons in the paraventricular nucleus. Circ. Res. 100, 1650-1658. doi: 10.1161/CIRCRESAHA.107.15 3494

Womack, M. D., Pyner, S., and Barrett-Jolley, R. (2006). Inhibition by alphatetrahydrodeoxycorticosterone (THDOC) of pre-sympathetic parvocellular neurones in the paraventricular nucleus of rat hypothalamus. $\mathrm{Br}$. J. Pharmacol. 149, 600-607. doi: 10.1038/sj.bjp.0706911

Yamashita, H., Inenaga, K., and Koizumi, K. (1984). Possible projections from regions of paraventricular and supraoptic nuclei to the spinal-cord - electrophysiological studies. Brain Res. 296, 373-378. doi: 10.1016/00068993(84)90077-5

Yang, Q., Chen, S. R., Li, D. P., and Pan, H. L. (2007). Kv1.1/1.2 channels are downstream effectors of nitric oxide on synaptic GABA release to preautonomic neurons in the paraventricular nucleus. Neuroscience 149, 315-327. doi: 10.1016/j.neuroscience.2007.08.007

Yoshimatsu, H., Egawa, M., and Bray, G. A. (1993). Sympathetic-Nerve activity after discrete hypothalamic injections of L-glutamate. Brain Res. 601, 121-128. doi: 10.1016/0006-8993(93)91702-T

Yu, F. H., and Catterall, W. A. (2003). Overview of the voltage-gated sodium channel family. Genome Biol. 4:207.

Zaki, A., and Barrett-Jolley, R. (2002). Rapid neuromodulation by cortisol in the rat paraventricular nucleus: an in vitro study. Br. J. Pharmacol. 137, 87-97. doi: $10.1038 /$ sj.bjp.0704832

Zhang, K., Li, Y. F., and Patel, K. P. (2002). Reduced endogenous GABAmediated inhibition in the PVN on renal nerve discharge in rats with heart failure. Am. J. Physiol. 282, R1006-R1015. doi: 10.1152/ajpregu.00241. 2001

Zhang, K., Mayhan, W. G., and Patel, K. P. (1997). Nitric oxide within the paraventricular nucleus mediates changes in renal sympathetic nerve activity. Am. J. Physiol. Regul. Integr. Comp. Physiol. 273, R864-R872. doi: 10.1152/ ajpregu.1997.273.3.R864
Zhang, Z., Zhao, Z., Margolskee, R., and Liman, E. (2007). The transduction channel TRPM5 is gated by intracellular calcium in taste cells. J. Neurosci. 27, 5777-5786. doi: 10.1523/JNEUROSCI.4973-06. 2007

Zheng, H., Liu, X., Li, Y., and Patel, K. P. (2014). Enhanced leptin-TRPC signaling in the hypothalamus contributes to the exaggerated sympatho-excitation in type 2 diabetic rats. FASEB J. 28:1130.9.

Zhong, M. K., Duan, Y. C., Chen, A. D., Xu, B., Gao, X. Y., De, W., et al. (2008). Paraventricular nucleus is involved in the central pathway of cardiac sympathetic afferent reflex in rats. Exp. Physiol. 93, 746-753. doi: 10.1113/ expphysiol.2007.041632

Zhou, J. J., Gao, Y., Kosten, T. A., Zhao, Z., and Li, D. P. (2017). Acute stress diminishes M-current contributing to elevated activity of hypothalamic-pituitary-adrenal axis. Neuropharmacology 114, 67-76. doi: 10.1016/j.neuropharm.2016.11.024

Zsombok, A., Gao, H., Miyata, K., Issa, A., and Derbenev, A. V. (2011). Immunohistochemical localization of transient receptor potential vanilloid type 1 and insulin receptor substrate 2 and their co-localization with liver-related neurons in the hypothalamus and brainstem. Brain Res. 1398, 30-39. doi: 10 1016/j.brainres.2011.04.048

Zubcevic, J., Waki, H., Raizada, M. K., and Paton, J. F. (2011). Autonomic-immune-vascular interaction: an emerging concept for neurogenic hypertension. Hypertension 57, 1026-1033. doi: 10.1161/ HYPERTENSIONAHA.111.169748

Conflict of Interest Statement: The authors declare that the research was conducted in the absence of any commercial or financial relationships that could be construed as a potential conflict of interest.

Copyright (c) 2018 Feetham, O'Brien and Barrett-Jolley. This is an open-access article distributed under the terms of the Creative Commons Attribution License (CC BY). The use, distribution or reproduction in other forums is permitted, provided the original author(s) and the copyright owner(s) are credited and that the original publication in this journal is cited, in accordance with accepted academic practice. No use, distribution or reproduction is permitted which does not comply with these terms. 